\title{
Impacts of the Atlantic Multidecadal Oscillation on the Relationship of the Spring Arctic Oscillation and the Following East Asian Summer Monsoon
}

\author{
SHANGFENG CHEN AND WeN CHEN \\ Center for Monsoon System Research, Institute of Atmospheric Physics, Chinese Academy of Sciences, and University of \\ Chinese Academy of Sciences, Beijing, China \\ RENGUANG WU \\ School of Earth Sciences, Zhejiang University, Hangzhou, and Center for Monsoon System Research, Institute of \\ Atmospheric Physics, Chinese Academy of Sciences, Beijing, China \\ LINYE SONG \\ Institute of Urban Meteorology, China Meteorological Administration, Beijing, China
}

(Manuscript received 23 December 2019, in final form 12 May 2020)

\begin{abstract}
Previous studies indicated that spring Arctic Oscillation (AO) can influence the following East Asian summer monsoon (EASM). This study reveals that the Atlantic multidecadal oscillation (AMO) has a pronounced modulation of the spring AO-EASM connection. Spring AO has a close relation with the EASM during the negative AMO (-AMO) phase. However, during the positive AMO (+ AMO) phase, the spring AO-EASM connection is weak. During the - AMO phase, a marked dipole atmospheric anomaly pattern (with an anticyclonic anomaly over the midlatitudes and a cyclonic anomaly over the subtropics) and a pronounced tripole sea surface temperature (SST) anomaly pattern is formed in the North Pacific during positive spring AO years. The cyclonic anomaly, SST, and precipitation anomalies over the subtropical western North Pacific (WNP) maintain and propagate southwestward in the following summer via a positive air-sea feedback, which further impacts the EASM variation. During the + AMO phase, the Pacific center of the spring AO (i.e., the anticyclonic anomaly over the midlatitudes) is weak. As such, the cyclonic anomaly cannot be induced over the subtropical WNP by the spring AO via wave-mean flow interaction. Hence, the spring AO-EASM connection disappears during the + AMO phase. The AMO impacts the Pacific center of the spring AO via modulating the Aleutian low intensity and North Pacific storm track intensity. The observed AMO modulation of the spring AO-EASM connection and Pacific center of the spring AO can be captured by the long historical simulation in a coupled global climate model.
\end{abstract}

\section{Introduction}

The East Asian summer monsoon (EASM) is one of the most important climate systems over East Asia during boreal summer (Tao and Chen 1987; Ding 1994; Wang et al. 2000; Huang et al. 2004; Chang et al. 2011). Abnormal behavior of the EASM can result in severe floods, droughts, and extreme temperature events over many parts of East Asia (Feng et al. 2000; Huang et al. 2000, 2003, 2012; Li et al. 2009; Zhai et al. 2016; Yuan et al. 2017). For example, the unusual EASM activity in

Corresponding author: Dr. Shangfeng Chen, chenshangfeng@ mail.iap.ac.cn summer of 1998 and 2016 resulted in severe flooding disasters around the Yangtze River valley and exerted pronounced impacts on the ecosystem, agriculture, human health, and socioeconomic development (Feng et al. 2000; Huang et al. 2000; Lau and Weng 2001; Zhai et al. 2016; Yuan et al. 2017). The abnormally strong EASM in 2018 was reported to lead to extreme heat waves and many casualties over East Asia, including northeast China, the Korean Peninsula, and Japan (Yuan et al. 2020). In particular, in 2018 China experienced the hottest summer since 1961 according to the meteorological records from the National Meteorological Information Center of China (Wang and Zhang 2018; Ding et al. 2019). Due to the pronounced impacts of the 
EASM variation on the East Asian climate, it is of great importance and has been a long-standing issue to investigate the factors of the EASM variation.

Interannual variation of the EASM was suggested to be impacted by a number of factors, including El NiñoSouthern Oscillation (ENSO) (Zhang et al. 1996; Wang et al. 2000; Chang et al. 2000; Huang et al. 2004; Xie et al. 2009; Wang et al. 2014; Li et al. 2014; Wu and Yu 2016; and references therein), sea surface temperature (SST) anomalies in the Indian and Atlantic Oceans (Xie et al. 2009; Wu et al. 2009; Rong et al. 2010; Zuo et al. 2013, 2019; Chen et al. 2018a), the western North Pacific subtropical high (WNPSH) (Lu 2002), the Pacific-Japan teleconnection (Nitta 1987; Huang and Sun 1992), Eurasian snow cover (Wu and Kirtman 2007; Zhao et al. 2007), and atmospheric systems over midhigh latitudes of Eurasia (Li et al. 2001; Gong et al. 2002; Gong and Ho 2003; Ding and Wang 2005).

The Arctic Oscillation (AO) is the first leading mode of atmospheric variability over extratropical Northern Hemisphere (NH) (Thompson and Wallace 1998, 2000). Studies demonstrated that boreal spring AO has a significant impact on the following EASM via modulating the WNPSH through the positive air-sea feedback processes over the North Pacific (Gong and Ho 2003; Gong et al. 2011). Gong et al. (2011) indicated that the impact of the spring AO on the EASM is independent of preceding winter ENSO. Two recent studies showed that the spring AO-EASM connection was unstable and experienced interdecadal change around the early 1970s (Chen et al. 2015) and mid-1990s (Gao et al. 2014). The time of change in the spring AO-EASM relation seems to coincide well with the phase transition of the Atlantic multidecadal oscillation (AMO), the leading mode of SST variability on the multidecadal time scales in the North Atlantic (Kerr 2000; Enfield et al. 2001). Furthermore, many recent studies indicated that the AMO has a significant interdecadal modulation effect on the climatological status over the North Pacific as well as on the connections between two climate systems (Zhang and Delworth 2007; Xiang et al. 2013; Peings and Magnusdottir 2014; Sun et al. 2017; Geng et al. 2017; Li et al. 2018; Park and Li 2019). For instance, Geng et al. (2017) reported that significant connection between the La Niña event and the East Asian winter monsoon could only be observed during the positive AMO (+ AMO) phase. The influence of ENSO on the tropical northern Atlantic SST only appeared during the negative AMO (-AMO) phase (Park and Li 2019). This evidence motivates us to ask a question: Can the relation between spring $\mathrm{AO}$ and the following EASM be modulated by the AMO? This issue has important implications for the prediction of EASM and climate variation over East
Asia. Hence, the main goal of this study to investigate the modulation effect of the AMO on the spring AOEASM relation as well as the underlying mechanisms related to this modulation effect.

The rest of the paper is organized as follows. Section 2 describes the data and methods. Section 3 presents the modulation effect of the AMO on the spring AOEASM relation based on observational data. Section 4 discusses the possible physical processes for the AMO impact on the spring AO-EASM connection. Based on historical simulations from a coupled climate model, the modulation effect of the AMO on the spring AOEASM connection is further examined in section 5 . A summary and discussion are provided in section 6 .

\section{Data and methods}

This paper uses monthly mean horizontal wind, geopotential height, sea level pressure, precipitation, and daily mean geopotential height from the National Centers for Environmental Prediction-National Center for Atmospheric Research (NCEP-NCAR) reanalysis dataset (Kalnay et al. 1996; https://www.esrl.noaa.gov/ $\mathrm{psd} /$ data/gridded/data.ncep.reanalysis.html). The daily mean geopotential height is used to calculate the synoptic-scale eddy activity (also called storm track). The NCEP-NCAR reanalysis data are available from 1948 to the present. The atmospheric data are on $2.5^{\circ} \times$ $2.5^{\circ}$ latitude-longitude grid, while the precipitation data are on T62 Gaussian grid. We also employ monthly mean atmospheric data from the Twentieth Century Reanalysis version 2 (20CRV2) (Compo et al. 2011; https://www.esrl.noaa.gov/psd/data/gridded/data. 20thC_ReanV2.html). The 20CRV2 dataset has a horizontal resolution of $2^{\circ} \times 2^{\circ}$ and is available from January 1871 to December 2012. This study uses two SST datasets, including the National Oceanic and Atmospheric Administration (NOAA) Extended Reconstructed SST version 3b (ERSSTv3b; Smith et al. 2008) and version 5 (ERSSTv5; Huang et al. 2017) (https://www.esrl.noaa.gov/psd/data/gridded/). These two SST datasets both have a regular $2^{\circ} \times 2^{\circ}$ latitudelongitude grid and span from January 1854 to the present. These two SST datasets lead to very similar results, and thus we only show the results based on the ERSSTv5 in the following. Furthermore, the monthly mean AMO index is extracted from the Physical Science Division of NOAA via the website https://www.esrl.noaa.gov/psd/ data/timeseries/AMO/, which has data available since January 1948. The monthly Pacific decadal oscillation (PDO) index is derived from https://www.esrl.noaa.gov/ $\mathrm{psd} / \mathrm{data} /$ correlation/pdo.data, covering the period of 1948-2018. The monthly North Pacific Gyre Oscillation 
(NPGO) index is obtained from http://www.o3d.org/ npgo/, which is available from January 1950 to July 2019.

Following previous studies (Thompson and Wallace 1998; Chen et al. 2014, 2017), the AO index is defined as the principal component (PC) time series corresponding to the first empirical orthogonal function (EOF) mode of SLP anomalies north of $20^{\circ} \mathrm{N}$. As in Chen et al. (2014, $2015)$, the storm track is defined as the root-meansquare of the 2-8-day bandpass filtered geopotential height anomalies at a specific pressure level. In this study, we employ three EASM indices (Wang et al. 1998; Wang and Fan 1999; Zhang et al. 2003). Wang et al. (1998) defined an EASM index using difference in the region-mean $\left(5^{\circ}-15^{\circ} \mathrm{N}, 90^{\circ}-130^{\circ} \mathrm{E}\right)$ zonal wind anomalies between 850 and $200 \mathrm{hPa}$ (the index is denoted herein as EASM-Wang98 for short). Wang and Fan (1999) defined an EASM index using difference in the 850 -hPa zonal wind anomalies averaged over $5^{\circ}-15^{\circ} \mathrm{N}$, $90^{\circ}-130^{\circ} \mathrm{E}$ and $22.5^{\circ}-32.5^{\circ} \mathrm{N}, 110^{\circ}-140^{\circ} \mathrm{E}$ (denoted as EASM-WF99). Zhang et al. (2003) defined an EASM index using difference in the $850-\mathrm{hPa}$ zonal wind anomalies averaged over $10^{\circ}-20^{\circ} \mathrm{N}, 100^{\circ}-150^{\circ} \mathrm{E}$ and $25^{\circ}-$ $35^{\circ} \mathrm{N}, 100^{\circ}-150^{\circ} \mathrm{E}$ (denoted as EASM-Zhang03). The western North Pacific subtropical high (WNPSH) index is defined as area-averaged geopotential height at $500 \mathrm{hPa}$ over $15^{\circ}-25^{\circ} \mathrm{N}$ and $120^{\circ}-135^{\circ} \mathrm{N}$ (Gong et al. 2011).

This paper analyzes the interannual relationship between the spring AO and the EASM. Hence, all the variables and the above defined indices are subjected to a 2-9-yr high-pass Lanczos filter to extract the interannual variation components (Duchon 1979). Significant levels of the correlation and regression coefficients are estimated based on a two-tailed Student's $t$ test.

\section{Interdecadal modulation of the spring AO-EASM connection by the AMO}

Figure 1a displays normalized time series of the spring [March-May (MAM)] AO index and the following summer three EASM indices from 1950 to 2016. Correlation coefficients of the spring AO index with the EASM-Wang98, EASM-WF99, and EASM-Zhang03 indices are $0.32,0.39$, and 0.38 over 1950-2016, respectively, all significant at the $99 \%$ confidence level. This suggests that spring AO has a close relationship with the following EASM variation, in concert with previous studies (Gong et al. 2011; Gao et al. 2014; Chen et al. 2015). However, the in-phase variation of the spring AO index with the EASM index is unstable. Figure $1 \mathrm{~b}$ displays 21-yr moving correlation coefficients of the spring AO index with the three EASM indices. Results based on the three EASM indices are similar. From Fig. 1b, the spring AO-EASM connection experienced pronounced
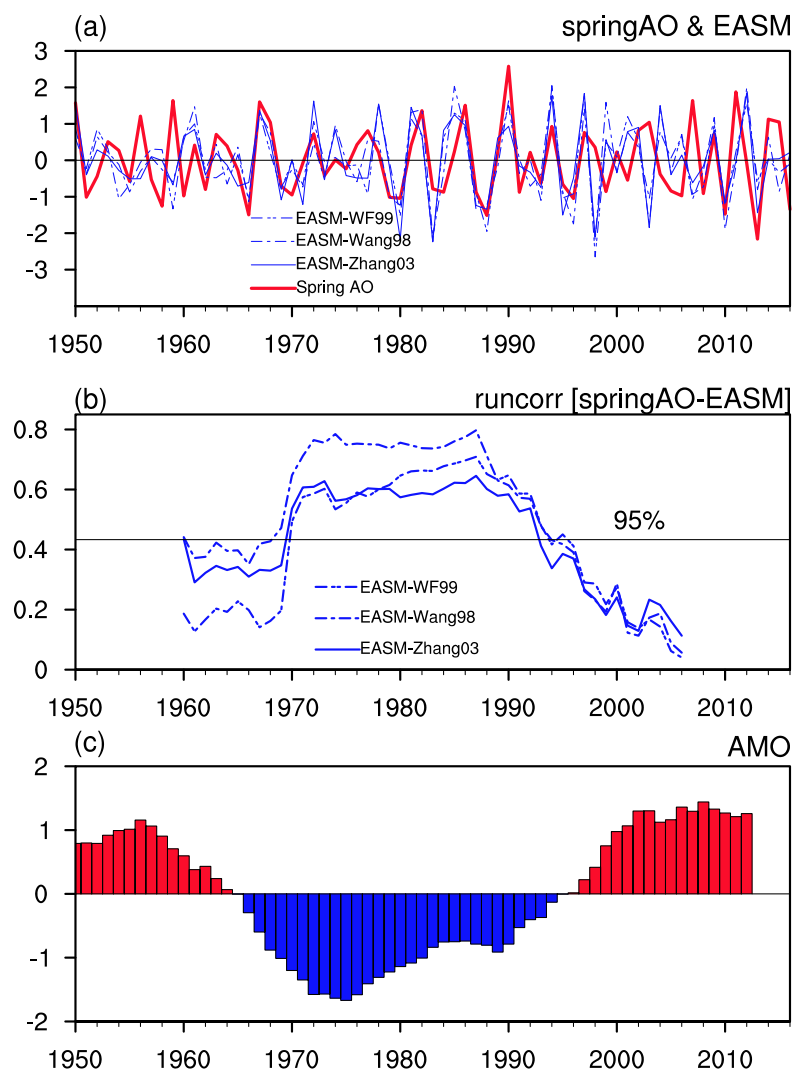

FIG. 1. (a) Normalized time series of the boreal spring (MAM average) AO index (red line) and three EASM indices (blue lines) for period of 1950-2016. (b) 21-yr moving correlation coefficients between the spring AO index and the three EASM indices. The horizontal line in (b) indicates the correlation significant at the 95\% confidence level. (c) Smoothed spring AMO index obtained from NOAA. Definitions of the three EASM indices are provided in the main text. The $+\mathrm{AMO}(-\mathrm{AMO})$ phase corresponds to the period of 1950-64 and 1997-2012 (1965-96).

interdecadal changes around the late 1960s and mid1990s, in accordance with Gao et al. (2014) and Chen et al. (2015). Specifically, the spring AO has a significant positive correlation with the EASM over the period from the late 1960s to the mid-1990s (Fig. 1b), corresponding to the -AMO phase (Fig. 1c). By contrast, during the + AMO phase (i.e., before the mid-1960s and after the mid-1990s), the connection of the spring AO with the EASM is weak and statistically insignificant (Figs. 1b,c).

Table 1 shows correlation coefficients of the spring AO index with the three EASM indices during two phases of the AMO. Here, the + AMO (-AMO) phase is defined as those years when the smoothed spring AMO index is larger (smaller) than zero (Fig. 1c). Based on this definition, the $+\mathrm{AMO}$ phase corresponds to the periods 1950-64 and 1997-2012. In addition, 1965-96 is considered as the -AMO phase. Note that results 
TABLE 1. Correlation coefficients of the spring AO index with the three EASM indices during different phases of the AMO, PDO, and NPGO. Spring AO and EASM indices are calculated based on the NCEP-NCAR reanalysis data. An asterisk (*) indicates that the correlation coefficient is significant at the $95 \%$ confidence level. Values in parentheses indicate that the winter (DJF) ENSO signal has been removed prior to calculating the correlation coefficient.

\begin{tabular}{lcclllr}
\hline \hline & + AMO & - AMO & +PDO & - PDO & + NPGO & - NPGO \\
\hline EASM-Wang98 & $-0.03(-0.2)$ & $0.78^{*}\left(0.71^{*}\right)$ & $0.56^{*}\left(0.45^{*}\right)$ & $0.25(0.17)$ & $0.14(-0.01)$ & $0.6 *\left(0.56^{*}\right)$ \\
EASM-WF99 & $-0.09(-0.22)$ & $0.71 *\left(0.64^{*}\right)$ & $0.48^{*}\left(0.36^{*}\right)$ & $0.14(0.07)$ & $0.12(-0.03)$ & $0.49 *\left(0.44^{*}\right)$ \\
EASM-Zhang03 & $0.02(-0.1)$ & $0.64 *\left(0.56^{*}\right)$ & $0.44^{*}\left(0.42^{*}\right)$ & $0.26(0.18)$ & $0.19(0.05)$ & $0.52 *(0.47 *)$ \\
\hline
\end{tabular}

obtained in the following analysis are not sensitive to the selection of the threshold value to define the AMO phases. For example, using the 0.1 or 0.2 standard deviation to select the $+\mathrm{AMO}$ and $-\mathrm{AMO}$ phases leads to similar results (not shown). The correlation coefficients of the spring AO index with the EASM-Wang98, EASM-WF99, and EASM-Zhang03 indices are as high as $0.78,0.71$, and 0.64 , respectively, during the - AMO phase (Table 1), all significant at the $99.9 \%$ confidence level. However, the spring AO-EASM connection is fairly weak during + AMO phase (Table 1). Gong et al. (2011) indicated that WNPSH plays an important role in relaying impact of the spring AO on the EASM. In addition, studies suggest that the WNPSH is one of the most important systems for the EASM (Ding 1994; Lu 2002; Chang et al. 2011; Gong et al. 2011). We have compared the connection of the spring AO index with the summer WNPSH index during different AMO phases. During the - AMO phase, spring AO has a significant positive correlation with the following summer WNPSH index $(r=0.58)$. In contrast, correlation of the spring AO with the summer WNPSH is weak and insignificant during the + AMO phase $(r=0.19)$.

ENSO is a dominant tropical driver of the EASM variation (Zhang et al. 1996; Wang et al. 2000; Huang et al. 2000; and references therein). In addition, studies have indicated that ENSO has a connection with the spring AO (e.g., Chen et al. 2014). This implies that the connection of the spring AO with the EASM could be impacted by the ENSO signal. To avoid potential impact of ENSO on the spring AO-EASM connection, the preceding winter ENSO signal has been removed from the spring AO index, EASM index, and other variables by means of linearly regression following Gong et al. (2011) and Chen et al. (2015). The winter [DecemberFebruary (DJF) average] ENSO signal is represented by the Niño-3.4 SST index, which is defined as region-mean SST anomalies over the region $5^{\circ} \mathrm{S}-5^{\circ} \mathrm{N}, 120^{\circ}-170^{\circ} \mathrm{W}$. Results indicate that the AMO still has a pronounced modulation effect on the spring AO-EASM relation after removal of the ENSO signal (Table 1). In the following analysis, the preceding winter ENSO signal has been removed unless otherwise stated.
Modulation effects of the AMO on the spring AOEASM relationship are further examined using the 20CRV2 atmospheric data and ERSST SST data from 1900 to 2012 (Fig. 2). Note that observed data are sparse before 1900 and less reliable, and thus are not considered (Deser et al. 2010; Smoliak and Wallace 2015; Wegmann et al. 2017). Here, the AMO index is defined as region-mean SST anomalies (the linear trend has

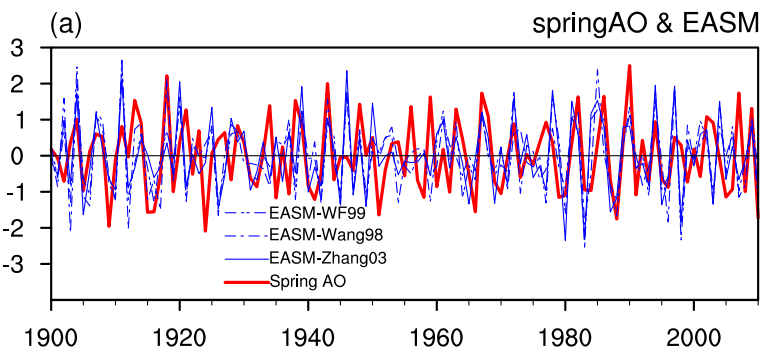

(b)
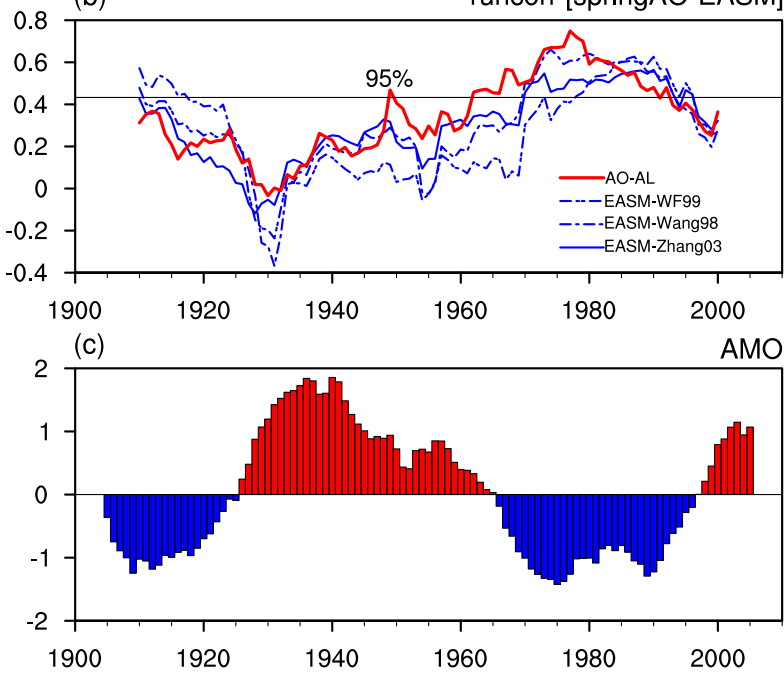

FIG. 2. (a) Normalized time series of the spring AO index (red line) and three EASM indices (blue lines). (b) 21-yr moving correlation coefficients of the spring AO index with the spring $\mathrm{AL}$ index (red line) and the three EASM indices (blue lines). Data used in constructing (a) and (b) are obtained from the 20CRV2 dataset. The horizontal line in (b) indicates the correlation significant at the 95\% confidence level. (c) Smoothed spring AMO index obtained from NOAA. Note that the AMO (-AMO) phase corresponds to the periods $1926-65$ and 1997-2005 (1905-25 and 1966-96). 
been removed) in the North Atlantic region $\left(0^{\circ}-60^{\circ} \mathrm{N}\right.$, $\left.0^{\circ}-80^{\circ} \mathrm{W}\right)$. In addition, the AMO index has been subjected to an 11-yr running mean to remove the variation on the interannual time scale. Modulation effects of the AMO on the spring AO-EASM connection can also be captured by the 20CRV2 (Fig. 2). In particular, the correlation coefficients of the spring AO index with the EASM-WF99, EASM-Wang98, and EASM-Zhang03 indices during the $-\mathrm{AMO}$ phase (a total of 52 years) are $0.49,0.57$, and 0.47 (Figs. 3b,d,f), respectively, all significant at the $99 \%$ confidence level. By contrast, relations of the spring AO with the EASM indices during + AMO phase are weak (Figs. 3a,c,e). Hence, the results derived from 20CRv2 are in good agreement with those obtained based on the more reliable period over 1948-2016 from the NCEP-NCAR reanalysis.

Figure 4 further displays spatial distributions of atmospheric circulation anomalies during the following summer obtained by regression upon the preceding spring $\mathrm{AO}$ index during + $\mathrm{AMO}$ and - $\mathrm{AMO}$ years, respectively. During - AMO years, significant negative SLP and 500-hPa geopotential anomalies extend eastward from the Indo-China Peninsula to the subtropical western North Pacific corresponding to the positive spring AO phase (Figs. 4b,f), indicating a significant weakened WNPSH. Correspondingly, a marked cyclonic anomaly occurs over the South China Sea, the Philippine Sea, and the subtropical western North Pacific (Fig. 4d). This anomalous cyclone plays an important role in modulating the EASM and associated precipitation anomalies over East Asia (Wang et al. 2000; Xie et al. 2009; Gong et al. 2011). Hence, the spring AO has a significant impact on the EASM variation during the $-\mathrm{AMO}$ phase (Figs. 1 and 2; Table 1).

During the + AMO phase, the negative SLP and 500hPa geopotential height anomalies over the western North Pacific shift considerably northward to around $40^{\circ} \mathrm{N}$. The atmospheric circulation anomalies related to the spring AO are weak over the South China Sea, the Philippine Sea, and the subtropical western North Pacific (Figs. 4a,c,e). Hence, spring AO has a weak impact on the EASM variation during the + AMO phase.

The evidence above collectively demonstrates that the AMO has a notable modulation effect on the spring AO-EASM connection. During the - AMO phase, the spring AO can exert notable impacts on the EASM variation. In contrast, the impact of the spring AO on the EASM is not robust during the + AMO phase.

\section{Factors for the modulation effect of the AMO on the spring AO-EASM connection}

The analyses in the above section suggest that there exist large differences in the summer atmospheric anomalies over the western North Pacific in association with the spring AO between the +AMO and - AMO phases (Fig. 4). In particular, the anomalous cyclone over the subtropical western North Pacific in summer induced by the preceding spring $\mathrm{AO}$ is stronger and located more southwestward during the -AMO phase. These differences in summer atmospheric anomalies over the western North Pacific explain changes in the spring AO-EASM connection with the AMO phase. Studies have demonstrated that the maintenance of the summer atmospheric anomalies over the subtropical western North Pacific related to the spring AO is mainly due to the positive air-sea interaction over the North Pacific (Gong et al. 2011; Chen et al. 2014). In the following, we compare the evolutions of spring AO-related SST, precipitation, and atmospheric anomalies between the two phases of AMO.

Figure 5 shows regression maps of $850-\mathrm{hPa}$ wind anomalies in MAM(0), April-June [AMJ(0)], and MayJuly $[\operatorname{MJJ}(0)]$ onto the normalized spring AO index for positive and negative AMO phases. Figures 6 and 7 exhibit the evolutions of associated SST and precipitation anomalies. Evolutions of the $850-\mathrm{hPa}$ winds, SST, and precipitation anomalies during the - AMO phase are in good agreement with previous studies (Gong et al. 2011; Chen et al. 2014). During simultaneous spring [i.e., MAM(0)], a marked meridional dipole atmospheric anomaly pattern appears over the North Pacific, with a notable cyclonic anomaly over subtropical westerncentral North Pacific and an anticyclonic anomaly over the midlatitudes (Fig. 5b). Accordingly, strong easterly wind anomalies are seen over the North Pacific between $30^{\circ}$ and $50^{\circ} \mathrm{N}$ and westerly wind anomalies are observed over the high latitudes and tropical western North Pacific (Fig. 5b). A marked tripole SST anomaly pattern is observed in the North Pacific in spring, with significant SST warming in the high latitudes around $40^{\circ}-50^{\circ} \mathrm{N}$ and in the tropical central Pacific extending northeastward to subtropical northeast Pacific, as well as significant SST cooling in the tropical Indian Ocean, the South China Sea, and the western North Pacific (Fig. 6b). The cyclonic anomaly and SST warming over the subtropical North Pacific are accompanied by significant positive precipitation anomalies (Figs. 5b, 6b, and 7b). As demonstrated by previous studies (Chen et al. 2014, 2017), the spring positive precipitation anomalies (indicating enhanced atmospheric heating) over the subtropical North Pacific in turn helps the maintenance of the cyclonic anomaly over the subtropical western North Pacific via a Gill-type atmospheric response (Gill 1980). The SST warming, positive precipitation anomalies, and cyclonic anomaly over the subtropical North Pacific are positively coupled with each other, which is favorable 

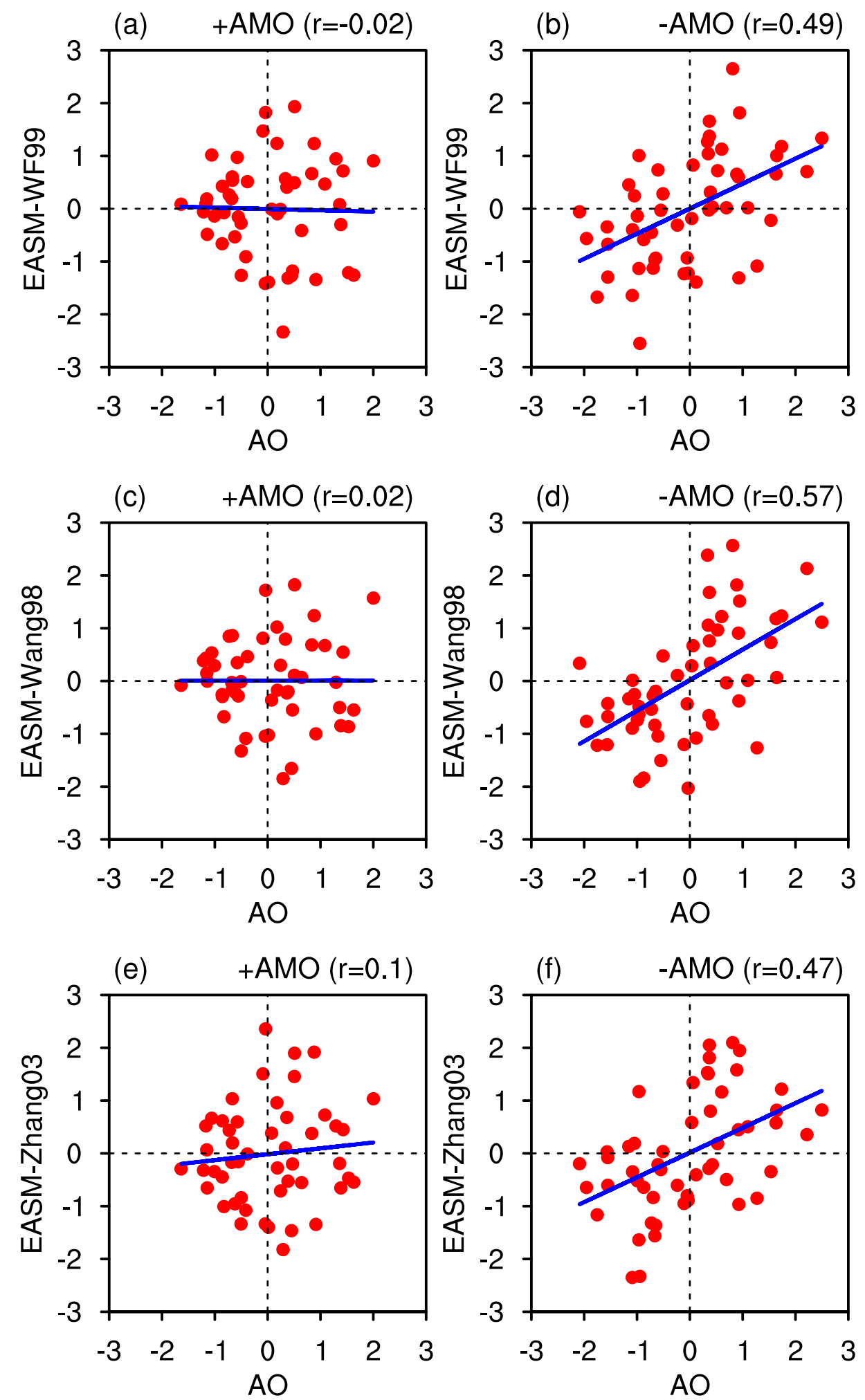

FIG. 3. Scatterplots of the spring AO index against the (a),(b) EASM-WF99, (c),(d) EASMWang98, and (e),(f) EASM-Zhang03 indexes for the (left) + AMO and (right) - AMO phases. This figure is constructed based on the data from the 20CRV2 dataset for the period of 1900-2012. The +AMO (-AMO) phase corresponds to periods 1926-65 and 1997-2005 (1905-25 and 1966-96). 

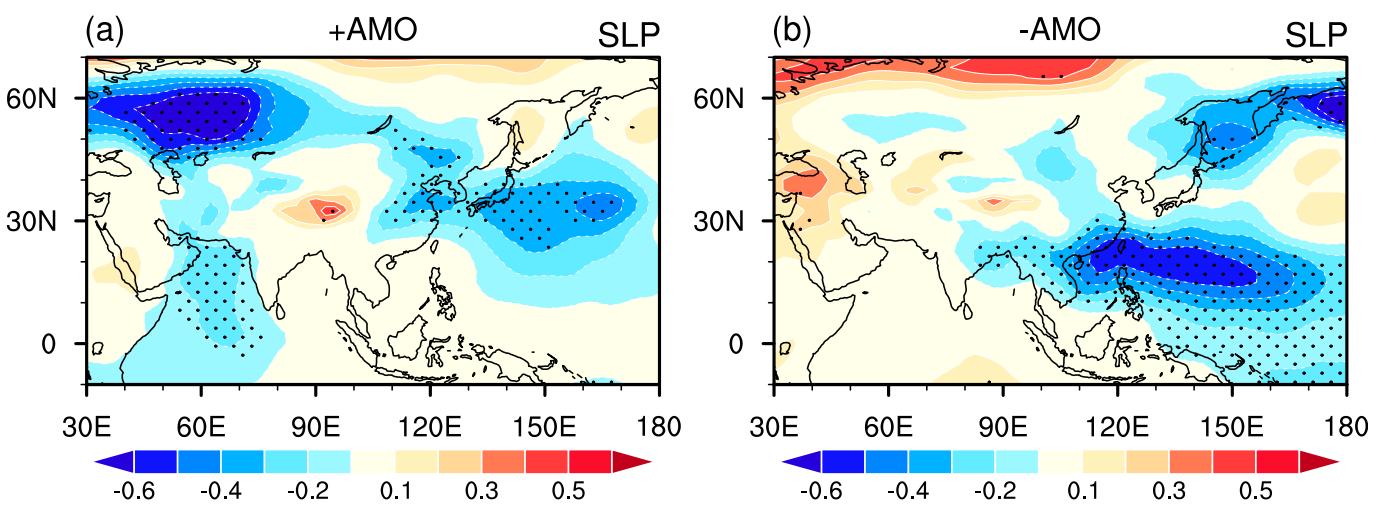

(c)

winds 850

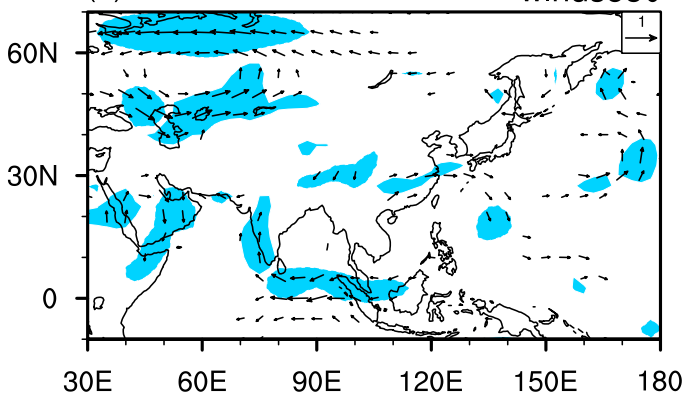

(d)

winds 850

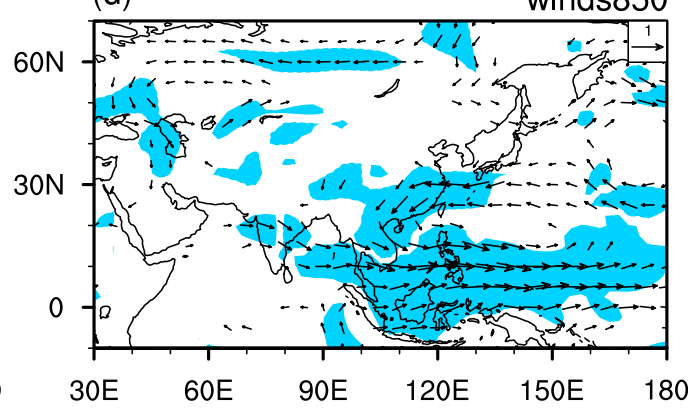

(e)

hgt500

(f)

hgt500
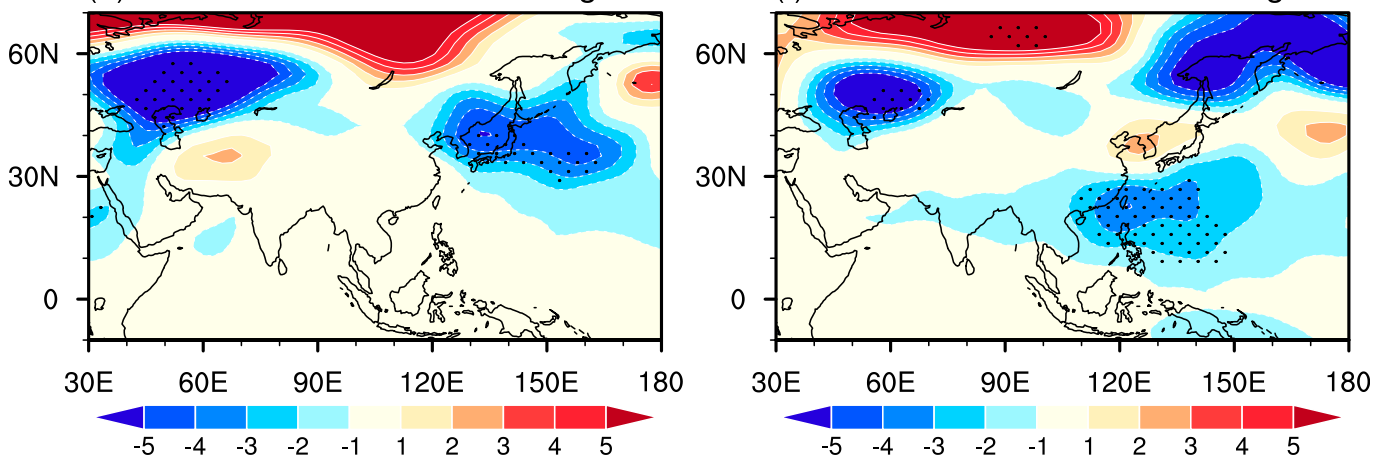

FIG. 4. Anomalies of summer (a),(b) SLP (hPa), (c),(d) winds at $850 \mathrm{hPa}\left(\mathrm{m} \mathrm{s}^{-1}\right)$, and (e),(f) geopotential height at $500 \mathrm{hPa}(\mathrm{m})$ regressed upon the preceding normalized spring AO index for the (left) + AMO and (right) - AMO phases. The shadings in (c) and (d) indicate either direction of the wind anomalies significant at the $95 \%$ confidence level. Wind anomalies in both directions less than $0.2 \mathrm{~m} \mathrm{~s}^{-1}$ in (c) and (d) are omitted. Stippled regions in (a), (b), (e), and (f) indicate anomalies significant at the $95 \%$ confidence level.

for maintenance and westward movement of the cyclonic anomaly induced by the spring AO (Gong et al. 2011; Chen et al. 2014). As such, the anomalous cyclone over the subtropical western North Pacific during the following summer induced by the preceding spring $\mathrm{AO}$ could exert significant impacts on the EASM and East Asian climate during the - AMO phase.

During the + AMO phase, the spring AO-related simultaneous atmospheric anomalies are much weaker over the North Pacific compared to those during the -AMO phase (Fig. 5a). In addition, due to the weak atmospheric anomalies, the SST anomalies in the subtropical North Pacific are statistically insignificant (Figs. 5a and 6a). This is consistent with previous studies that generation of the spring SST anomalies in the North Pacific are mainly attributed to surface heat flux changes induced by the spring AO-related atmospheric anomalies (Gong et al. 2011; Hu et al. 2013; Chen et al. 2014). Furthermore, the positive precipitation anomalies over the subtropical North Pacific in spring are also much weaker during + AMO than -AMO phases (Figs. 7a,b). Due to the weak atmospheric, SST, and precipitation 


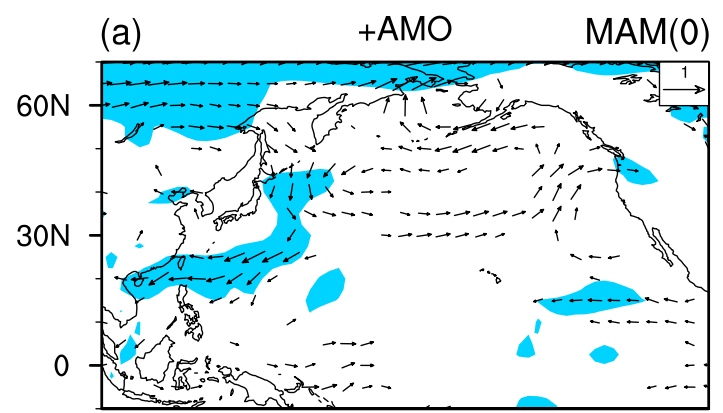

(c)

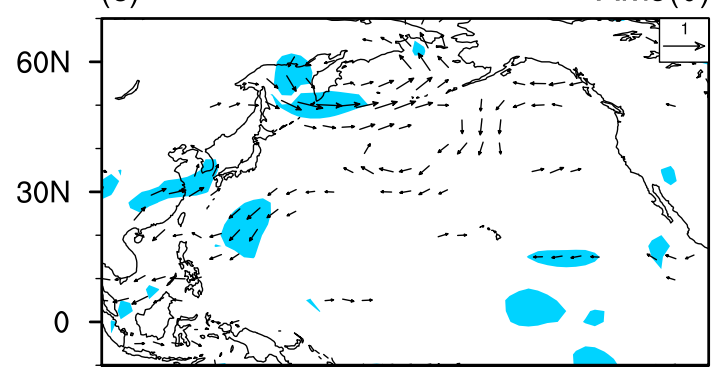

(e)

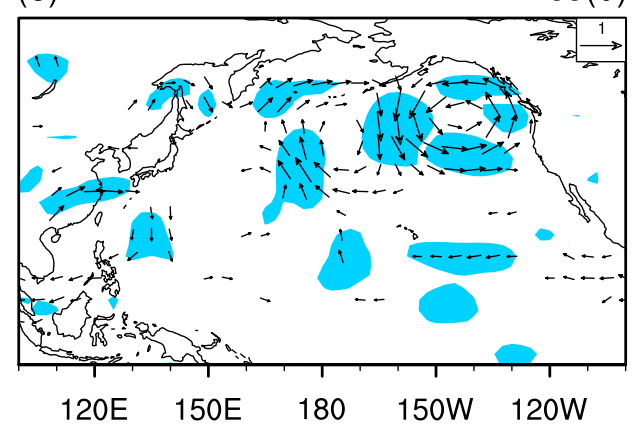

(b)

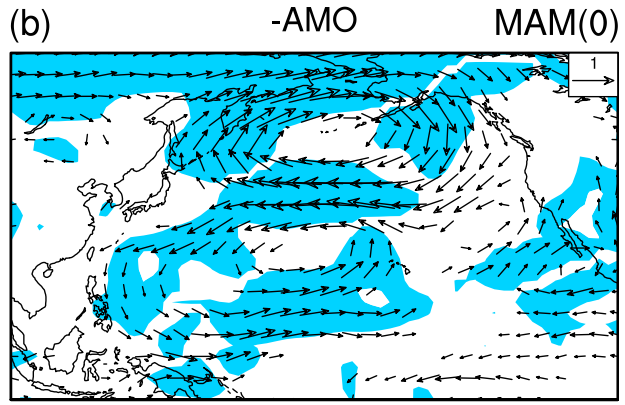

(d)

$\operatorname{AMJ}(0)$

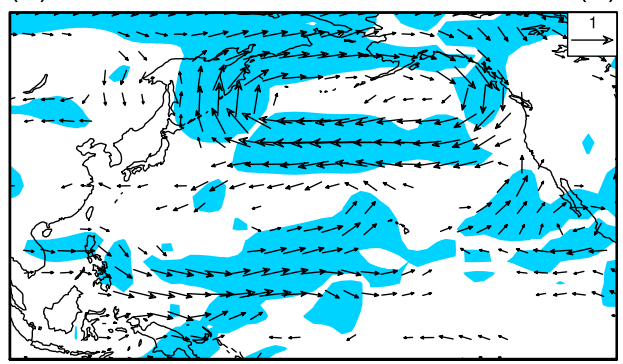

(f)

$\operatorname{MJJ}(0)$

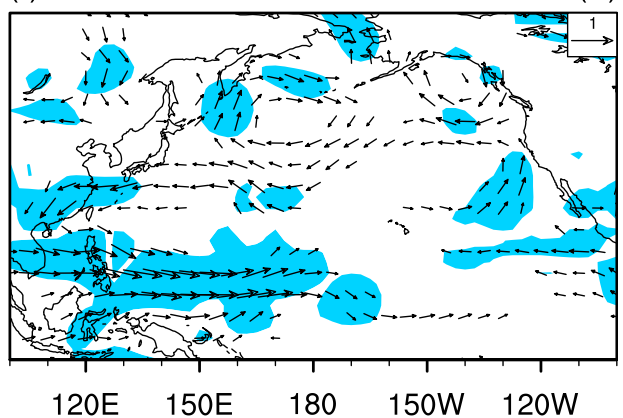

FIG. 5. Anomalies of 850-hPa winds $\left(\mathrm{m} \mathrm{s}^{-1}\right.$ ) in (a),(b) MAM(0), (c),(d) $\operatorname{AMJ}(0)$, and (e),(f) MJJ(0) regressed upon the normalized spring AO index for the (left) + AMO and (right) - AMO phases. The shadings in (a)-(f) indicate either direction of the wind anomalies significant at the $95 \%$ confidence level. Wind anomalies in both directions less than $0.2 \mathrm{~m} \mathrm{~s}^{-1}$ are omitted in (a)-(f).

anomalies in spring, the cyclonic anomaly cannot be clearly observed over the subtropical North Pacific in the following summer during the + AMO phase via positive air-sea feedback (Gong et al. 2011; Chen et al. 2014, 2015). Hence, this explains the weak spring AOEASM connection during the + AMO phase.

The above analysis suggests that there exist large differences in the spring AO-associated atmospheric circulation anomalies over the North Pacific, in particular the anomalous cyclone over the subtropics. As indicated by previous studies (Gong et al. 2011; Chen et al. 2014, 2017), formation of the cyclonic anomaly over the subtropical North Pacific related to the spring AO can be attributed to the interaction between synoptic-scale eddy and low-frequency mean flow and the associated vorticity transportation. The processes can be summarized as follows. The easterly wind anomalies over the North Pacific around $30^{\circ}-50^{\circ} \mathrm{N}$ to the south of the anomalous anticyclonic (i.e., Pacific component of the spring AO) are associated with weakened synoptic-scale eddies activity (not shown) (Lau 1988; Chen et al. 2014). As demonstrated by Lau (1988) and Cai et al. (2007), weakening of the synoptic-scale eddies is immediately accompanied by anticyclonic vorticity forcing to the north, which sustains the spring AO's Pacific component, consistent with the evidence that the wave-mean flow interaction plays a key role in forming and maintaining the AO-related atmospheric circulation anomalies (Limpasuvan and Hartmann 1999, 2000; Lorenz and Hartmann 2003; Thompson et al. 2003). In addition, 

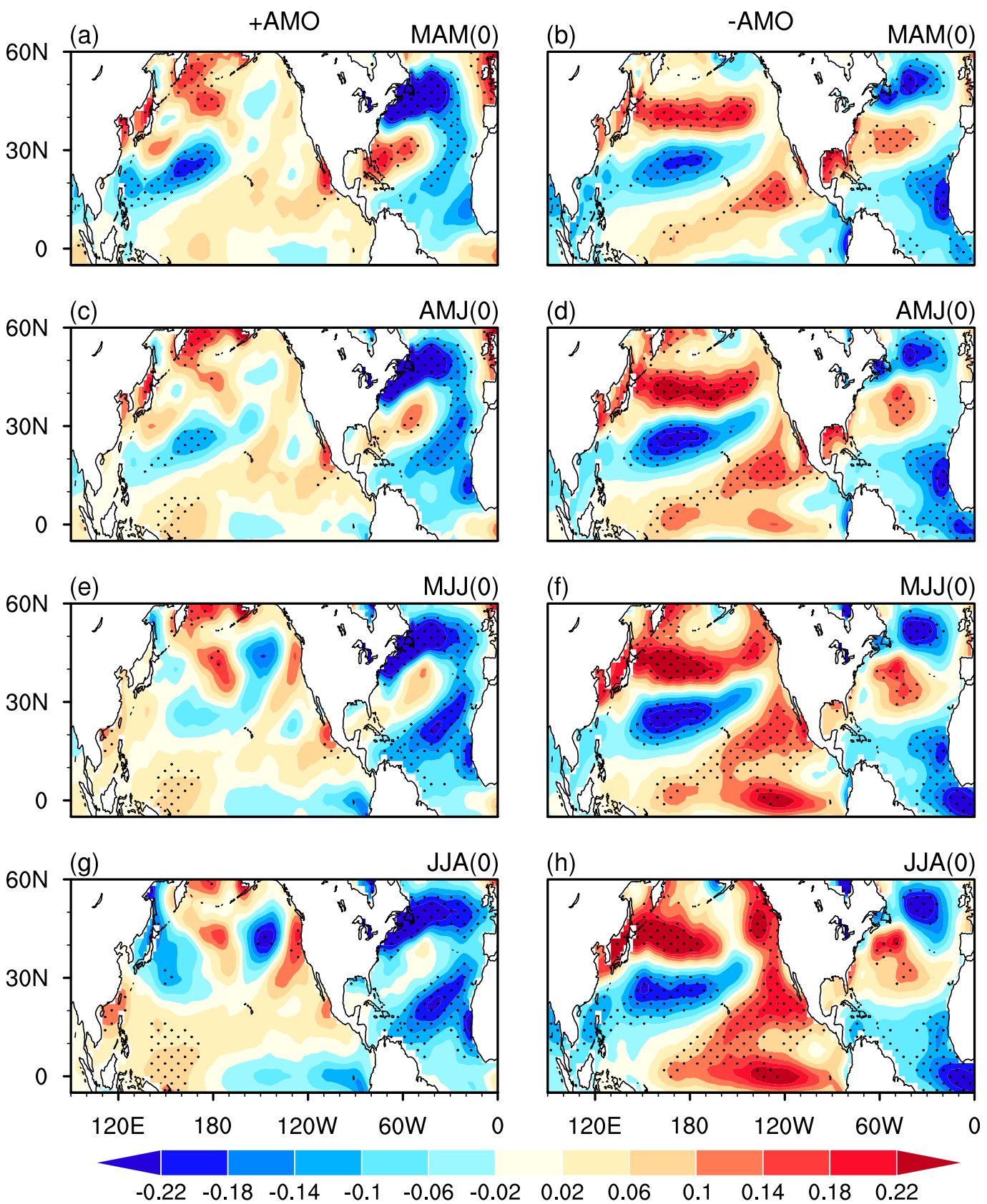

FIG. 6. Anomalies of SST $\left({ }^{\circ} \mathrm{C}\right)$ in (a),(b) MAM(0), (c),(d) $\operatorname{AMJ}(0)$, (e),(f) MJJ(0), and (g),(h) JJA(0) regressed upon the normalized spring AO index for the (left) + AMO and (right) - AMO phases. Stippling regions in (a)-(h) indicate SST anomalies significant at the $95 \%$ confidence level.

the associated cyclonic vorticity forcing to the south explains the formation of the anomalous cyclone over the subtropical North Pacific (Gong et al. 2011; Chen et al. 2014, 2015). During the +AMO phase, the anticyclonic anomaly over the midlatitude North Pacific (i.e., the spring AO's Pacific component) and associated easterly wind anomalies to its southern flank are much weaker and shift northward compared to those during the -AMO phase. Therefore, the spring AO-generated cyclonic anomaly over the subtropical North Pacific is much weaker during the + AMO phase.

The analysis above suggests that modulation of the AMO on the spring AO-EASM connection may be mainly via changing the Pacific component of the spring AO (i.e., anomalous anticyclone over the midlatitudes). Differences in the anomalous anticyclone over the 

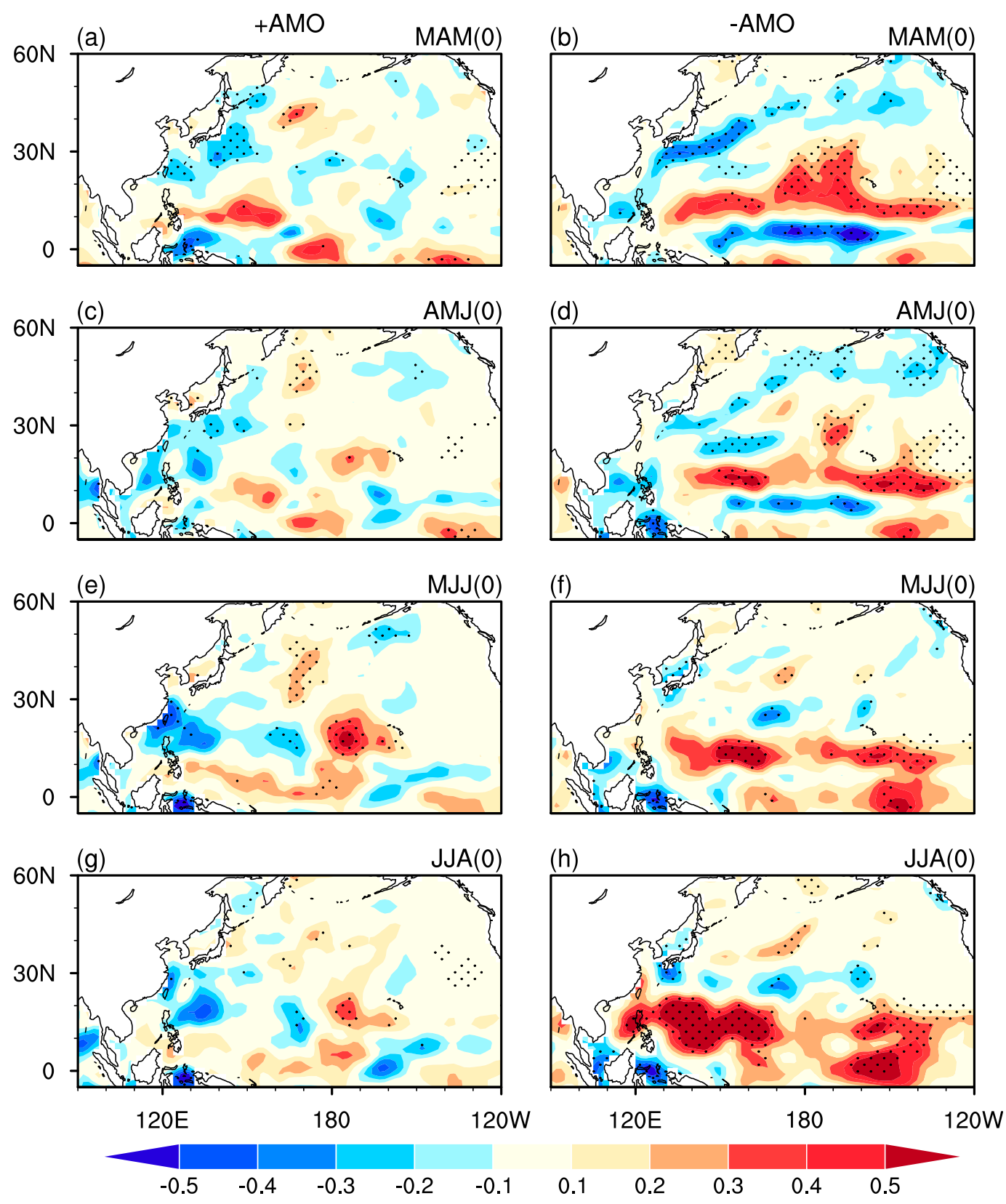

FIG. 7. Anomalies of precipitation $\left(\mathrm{mm} \mathrm{day}^{-1}\right)$ in (a),(b) MAM(0), (c),(d) AMJ(0), (e),(f) MJJ(0), and (g),(h) JJA(0) regressed upon the normalized spring AO index for the (left) + AMO and (right) - AMO phases. Stippling regions in (a)-(h) indicate precipitation anomalies significant at the $95 \%$ confidence level.

North Pacific between different phases of the AMO further lead to differences in the anomalous cyclone over the subtropical North Pacific via wave-mean flow interaction.

Figure 8 further displays regression maps of SLP and 500 -hPa geopotential height anomalies north of $20^{\circ} \mathrm{N}$ in spring onto the spring $\mathrm{AO}$ index during the $+\mathrm{AMO}$ and - AMO phases. During the - AMO phase, SLP and geopotential height anomalies show a more zonally symmetrical structure, with significant negative anomalies over the Arctic region and positive anomalies over the midlatitudes of the North Pacific and North Atlantic, respectively (Figs. 8b,d). It is noted that significant negative SLP and geopotential height anomalies can be found over the subtropical North Pacific to the southward flank of the spring AO's Pacific center, corresponding to significant cyclonic anomaly there (Figs. 8b,d). By contrast, during the $+\mathrm{AMO}$ phase, the Pacific center of 

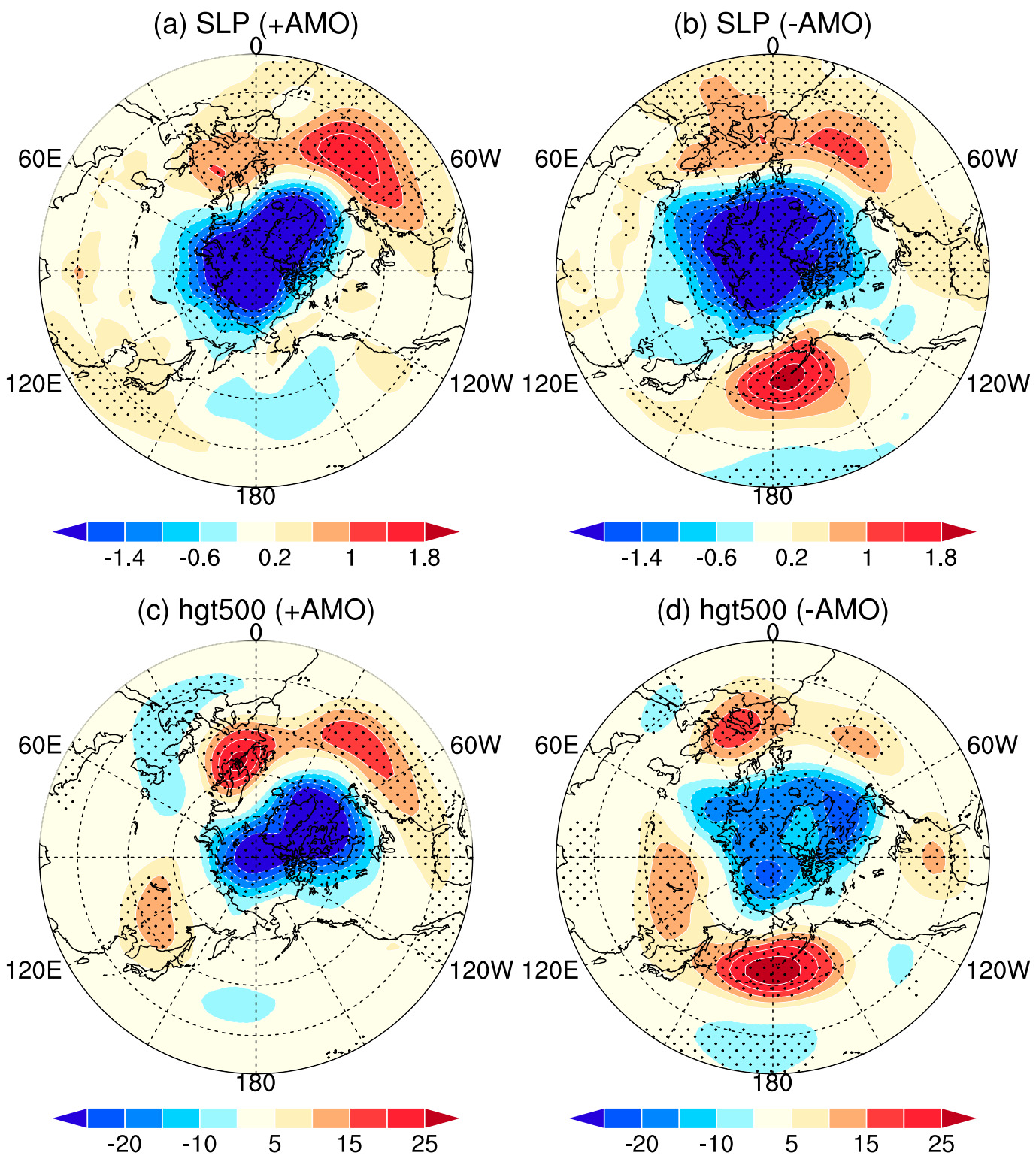

FIG. 8. Anomalies of (a),(b) spring SLP (hPa) and (c),(d) 500-hPa geopotential height (m) regressed upon the simultaneous normalized spring AO index for the (left) + AMO and (right) - AMO phases. Stippling regions indicate anomalies significant at the $95 \%$ confidence level.

the spring AO (i.e., positive SLP and geopotential height anomalies over the midlatitude North Pacific) is unclear. As a result, the associated atmospheric circulation anomalies over the subtropical North Pacific are weak. During the + AMO phase, significant signals of the atmospheric anomalies of spring AO are mainly confined to the North Atlantic, which is reminiscent of the North Atlantic Oscillation (Hurrell 1995; Hurrell and van Loon 1997). Studies indicated that Pacific center of the AO tends to have a relation to the PNA and Aleutian low (AL) (Sun and Tan 2013; Dai and Tan 2017). We have examined the 21-yr moving correlation between the spring AO index and the AL intensity index (Fig. 2b, red line). The spring AL intensity index (ALI) is defined as areaaveraged SLP anomalies over the region $50^{\circ}-65^{\circ} \mathrm{N}$, $160^{\circ} \mathrm{E}-145^{\circ} \mathrm{W}$ according to the spatial structure of climatological mean SLP (Fig. 9a). From Figs. 2b and 2c, it is obvious that the AMO has a notable modulation on the spring AO-AL relation. The spring AO-AL connection is stronger during negative than positive phases of the AMO. In particular, the correlation coefficient of the spring AO index with the spring ALI is 0.5 during the 
(a)

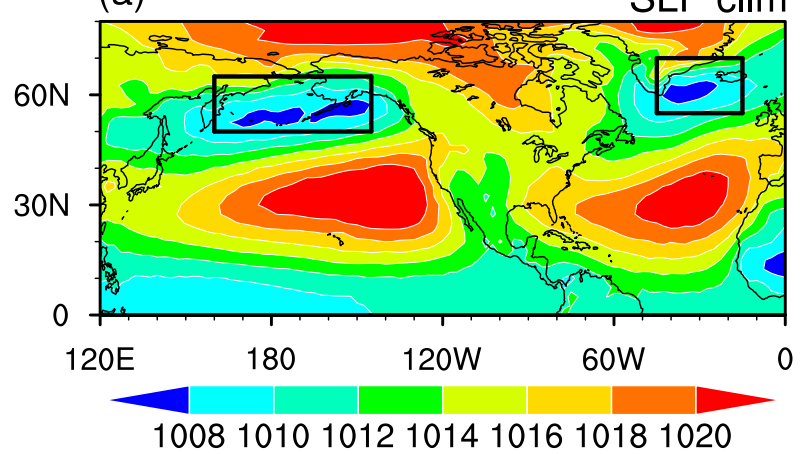

(b)

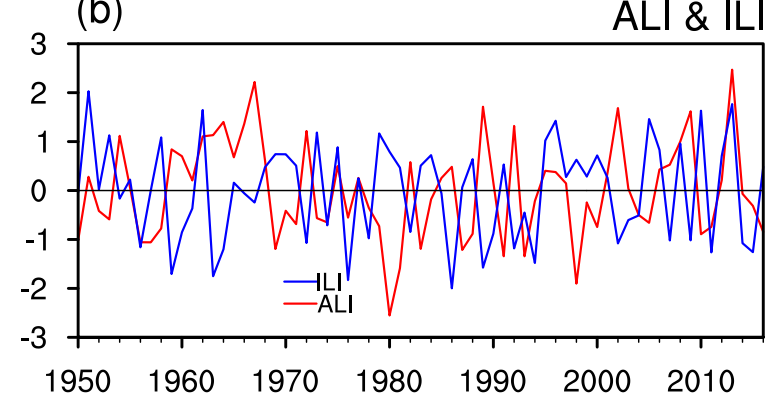

(c)

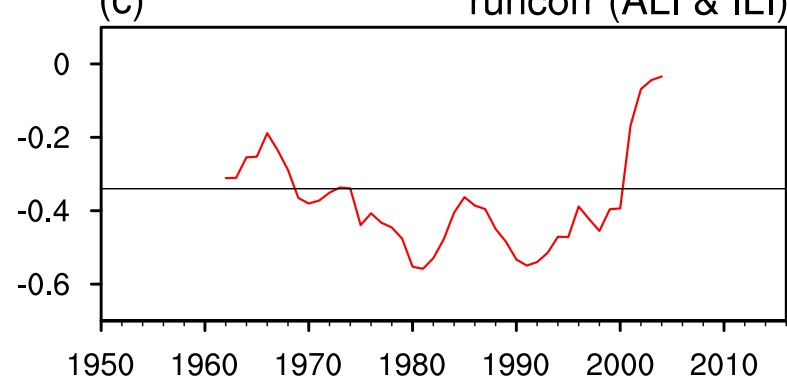

FIG. 9. (a) Spatial distribution of the spring climatological mean SLP (hPa) for period of 1950-2016. The boxes over the North Pacific and North Atlantic are employed to define the Aleutian low intensity index (ALI) and the Icelandic low intensity index (ILI), respectively. (b) Normalized time series of the spring ALI and the ILI from 1950 to 2016. (c) 21-yr moving correlation coefficients between the spring ALI and ILI. The horizonal line in (c) indicates the correlation significant at the $95 \%$ confidence level.

negative AMO phase, significant at the $99 \%$ confidence level. By contrast, the relation of the spring $\mathrm{AO}$ with the spring ALI is weak during the positive AMO phase ( $r=$ $0.04)$. These results confirm that the Pacific center of the spring $\mathrm{AO}$ and the spring $\mathrm{AO}-\mathrm{AL}$ connection shows large differences between the $+\mathrm{AMO}$ and $-\mathrm{AMO}$ phase. These large differences explain the significant modulation effect of the AMO on the spring AO-EASM relation.

The AO is the leading mode of SLP anomalies over the extratropical Northern Hemisphere, generally with three centers of action over Arctic, North Pacific, and North Atlantic, respectively (Thompson and Wallace
1998). The North Atlantic center of the AO has a significant correlation with the North Atlantic Oscillation (NAO), which is characterized by a seesaw in SLP field between the Icelandic low (IL) and Azores high (Hurrell 1995). Meanwhile, the North Pacific center of the AO tends to have a relation with the PNA as well as the Aleutian low (Honda and Nakamura 2001; Wallace and Thompson 2002; Sun and Tan 2013; Cheng and Tan 2019). Several studies have suggested that the AO can be considered as a combination of the NAO and the PNA pattern (Honda and Nakamura 2001; Sun and Tan 2013; Dai and Tan 2017; Cheng and Tan 2019). Studies also indicate that the North Atlantic center of the AO always exists and $\mathrm{AO}$ has a stable relation with the NAO. However, the Pacific center of the AO shows significant interdecadal changes (Sun and Tan 2013; Shi and Nakamura 2014). Sun and Tan (2013) and Shi and Nakamura (2014) reported that the Pacific center of the AO is strong (weak) when the out-of-phase relation of the AL with the IL is strong (weak). The out-of-phase variation of the AL and the IL is regarded as the AL-IL oscillation, first proposed by Honda and Nakamura (2001).

In the following, we compare the AL-IL oscillation between + AMO and - AMO phases. Figure 9a displays the climatological mean of spring SLP during 1950 2016. The low pressure system over the North Pacific (Atlantic) corresponds to the AL (IL). Based on spatial structure of climatological mean SLP, the IL intensity index (ILI) is defined as area-averaged SLP anomalies over the region of $55^{\circ}-70^{\circ} \mathrm{N}$ and $15^{\circ}-45^{\circ} \mathrm{W}$ (Figs. 9a,b). Figure $9 \mathrm{c}$ displays 21-yr moving correlation coefficients between the spring ALI and ILI. The ALI-ILI connection is weak before the mid-1960s and after the late 1990s, corresponding to the +AMO phase. By contrast, interannual variation of the spring ALI has a close relation with the ILI variation during the - AMO phase. The above results suggest that the AMO has a notable modulation effect on the spring ALI-ILI oscillation, which explains the differences in the Pacific center of the spring $\mathrm{AO}$ between the $+\mathrm{AMO}$ and $-\mathrm{AMO}$ phases.

How can the AMO modulate the spring ALI-ILI connection? Studies indicated that appearance of the AL-IL oscillation is associated with the horizontal atmospheric Rossby wave train propagating eastward from the midlatitudes North Pacific across North America to the North Atlantic, bearing some resemblances to the PNA teleconnection (Honda and Nakamura 2001; Sun and Tan 2013). Honda and Nakamura (2001) indicated that the appearance of the AL-IL oscillation was related to a PNA-like atmospheric Rossby wave train. Sun and Tan (2013) argued that interannual variations of the ALI and ILI were connected through an eastern Pacific atmospheric wave (EPW). Zhou et al. (2012) showed that 
(a)

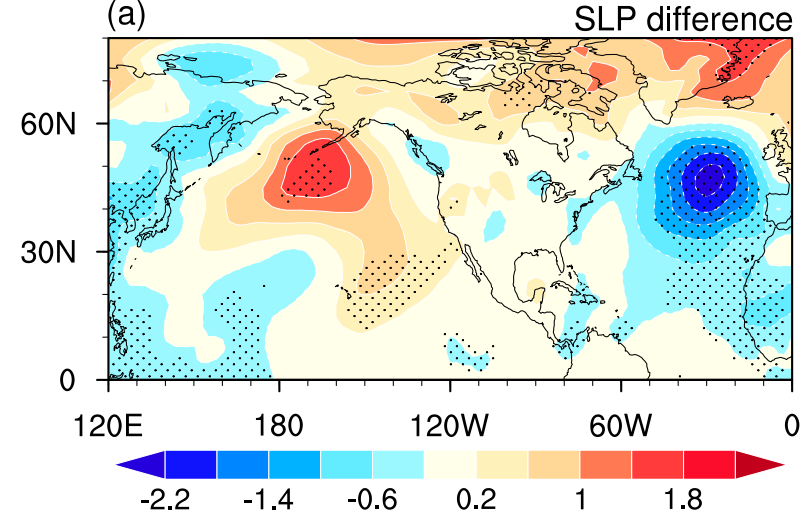

(b)

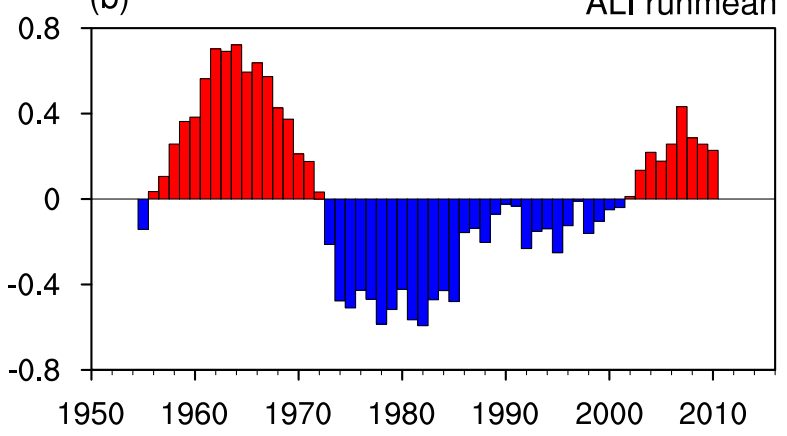

FIG. 10. (a) Difference in the spring climatological mean SLP $(\mathrm{hPa})$ between $+\mathrm{AMO}$ and $-\mathrm{AMO}$ phases. Stippling regions indicate the differences that are significantly different from zero at the $95 \%$ confidence level. (b) 21-yr moving average of the normalized spring ALI.

the EPW and the PNA are the same phenomenon as described by different variables. Specifically, the EPW is described by the wave activity flux, and the PNA is described by the geopotential height anomalies. Sun and Tan (2013) demonstrated that if the EPW is strong enough, significant AL-IL oscillation can be established due to the EPW. They showed that strength of the EPW is directly determined by strength of the ALI. Specifically, stronger (weaker) ALI results in stronger EPW and contributes to a stronger (weaker) AL-IL oscillation because the induced wave activity flux propagating eastward from the midlatitudes North Pacific to the North Atlantic is much stronger (weaker). This highlights the important role of the ALI intensity in modulating the AL-IL oscillation.

Figure 10a presents the difference in climatological spring SLP between the +AMO and - AMO phase. Significant negative SLP anomalies are seen over the North Atlantic, which were induced by the North Atlantic SST warming related to the AMO (Zhang and Delworth 2007; Sun et al. 2017). In addition, pronounced positive SLP anomalies are found over the North Pacific where the Aleutian low is generally located. This implies a significant weakening (enhancement) of the Aleutian low intensity during positive (negative) AMO years. This can be further confirmed by the result shown in Fig. 10b that displays the 21-yr moving mean of the standardized spring ALI. The standardized ALI tends to larger (less) than zero during the +AMO (-AMO) years, conforming stronger ALI during the - AMO years. Note that phase transition of the AMO tends to be earlier than that of the AL intensity (Figs. 1c and 10b), consistent with previous studies (e.g., Zhang and Delworth 2007; Sun et al. 2017). Zhang and Delworth (2007) and Sun et al. (2017) indicated that AMO can exert a significant lagged impact on the PDO and AL intensity via atmospheric teleconnection and positive airsea interaction feedback over the North Pacific.

Impacts of the AMO on the ALI on the interdecadal time scales may occur via atmospheric teleconnection, as has been demonstrated by previous studies (Sun et al. 2017, please see their Fig. 7; Yang et al. 2019). In particular, as indicated by Sun et al. (2017), the SST warming in the midlatitude North Atlantic (Fig. 11a) in the +AMO phase can lead to pronounced upward motion and positive precipitation (Fig. 11b), which is generally accompanied by lower-level convergence and upper-level divergence anomalies (Sun et al. 2017). The outflows related to the upper-level divergence over the North Atlantic converge over the midlatitudes North Pacific and result in compensating downward motion and negative precipitation (Fig. 11b). This contributes to positive SLP anomalies and weakening of the ALI. The conditions are reverse for the -AMO phase. Through the above-mentioned processes, AMO could exert significant impacts on the SLP climatology over the North Pacific and thus the ALI (Sun et al. 2017). This result suggests that the AMO may modulate the spring ALI-ILI connection via changing the AL intensity, which further alters the Pacific component of the spring $\mathrm{AO}$ and the spring AO-EASM connection.

Chen et al. (2015) indicated that interdecadal enhancements of the spring AO-related atmospheric circulation anomalies over the North Pacific as well as the spring AO-EASM relation around the early 1970s are attributed to interdecadal increase in the strength of the North Pacific storm track. In particular, an increase in the strength of storm track would result in a stronger eddy feedback to the mean flow, which explains a stronger spring AO-generated atmospheric circulation anomalies over the North Pacific via eddy-mean flow interaction process (Chen et al. 2015; please see their Figs. 9-11). This implies that the AMO may also impact the spring AO-related atmospheric circulation anomalies over the North Pacific via modulating the strength of the North Pacific storm track. Actually, previous studies have shown that the North Pacific storm track is 

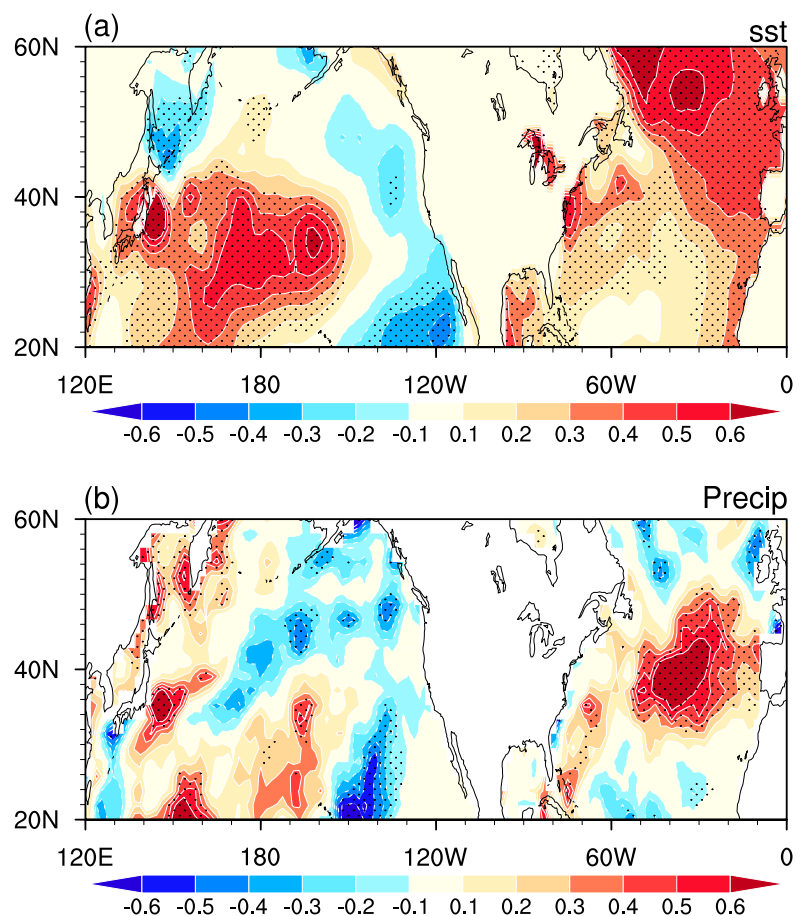

FIG. 11. Difference in the spring climatological mean (a) SST $\left({ }^{\circ} \mathrm{C}\right)$ and precipitation $\left(\mathrm{mm} \mathrm{day}^{-1}\right)$ between + AMO and - AMO phases. Stippling regions indicate the differences that are significantly different from zero at the $95 \%$ confidence level

strengthened and shifts southeastward during negative AMO phases (Zhang and Delworth 2007), which can also be confirmed by Fig. 12, which shows the difference in the springtime storm track between the + AMO and $-\mathrm{AMO}$ phases (+ AMO minus - AMO). Hence, the enhanced North Pacific storm track during the - AMO phase may also partly contribute to stronger spring AOrelated atmospheric circulation anomalies over North Pacific via eddy-mean flow interaction, which further result in a closer spring AO-EASM connection during the - AMO phase.

\section{Modulation of the AMO on the spring AO-EASM relation in a coupled model historical simulation}

In the following, the modulation of the AMO on the relationship between the spring $\mathrm{AO}$ and following EASM is examined in a historical simulation of the Beijing Normal University Earth System Model (BNUESM). BNU-ESM is a fully coupled model, developed by the College of Global Change and Earth System Science at Beijing Normal University. The atmospheric component in BNU-ESM is an interim version of the Community Atmospheric Model version 4 (CAM4),

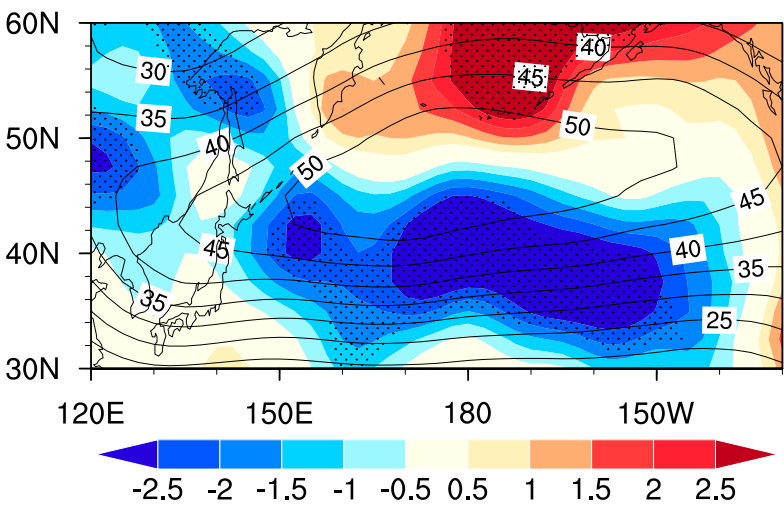

FIG. 12. Difference in the spring climatological mean storm track (m) between the $+\mathrm{AMO}$ and - AMO phases. Stippling regions indicate the differences that are significantly different from zero at the $95 \%$ confidence level.

with a horizontal resolution of about $2.81^{\circ} \times 2.81^{\circ}$ (Neale et al. 2013). The ocean component is developed according to the Geophysical Fluid Dynamics Laboratory Modular Ocean Model version 4p1 (Griffies $2010)$, with a horizontal resolution of about $1^{\circ} \times 1^{\circ}$ over the extratropics and about $0.33^{\circ} \times 0.33^{\circ}$ in the tropics $\left(10^{\circ} \mathrm{S}-10^{\circ} \mathrm{N}\right)$. The sea ice component in BNU-ESM is the Los Alamos Sea Ice Model version 4.1 (Hunke and Lipscomb 2010). In addition, the BNU-ESM land component is the Common Land Model (Dickinson et al. 1993). More detailed descriptions of the BNU-ESM can be found in Ji et al. (2014).

The BNU-ESM experiment employed in the following is the historical simulation from 1850 to 2005 forced by the observed forcing, including the time-varying greenhouse gas concentrations, solar radiation, aerosols, and so on. Gao et al. (2016) indicated that the BNU-ESM is one of the limited models participating in CMIP5 that can well reproduce the significant spring AO-EASM connection and the underlying processes. Furthermore, Joshi and Ha (2019) reported that the BNU-ESM can well simulate the spatial pattern of the AMO. Hence, it is reasonable to employ the BNU-ESM simulation to examine modulation of the AMO on the spring AO-EASM connection. Following Gao et al. (2016), the summer in the BNU-ESM simulation denotes the average for May-July (MJJ) because the correlation between spring AO index and the WNPSH in MJJ is the most significant. Definitions of the spring AO index and the EASM index (except using MJJ data) in the BNU-ESM simulation are similar to the observed. In addition, similar to previous studies (Kavvada et al. 2013; Joshi and Ha 2019), the AMO index is defined as detrended spring SST anomalies averaged over the North Atlantic (i.e., $0^{\circ}-60^{\circ} \mathrm{N}, 0^{\circ}-80^{\circ} \mathrm{W}$ ). 
(a)

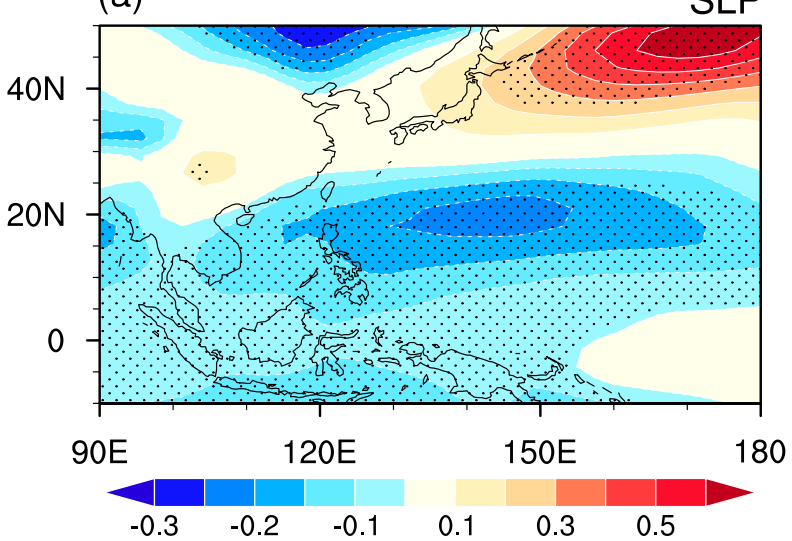

(b)

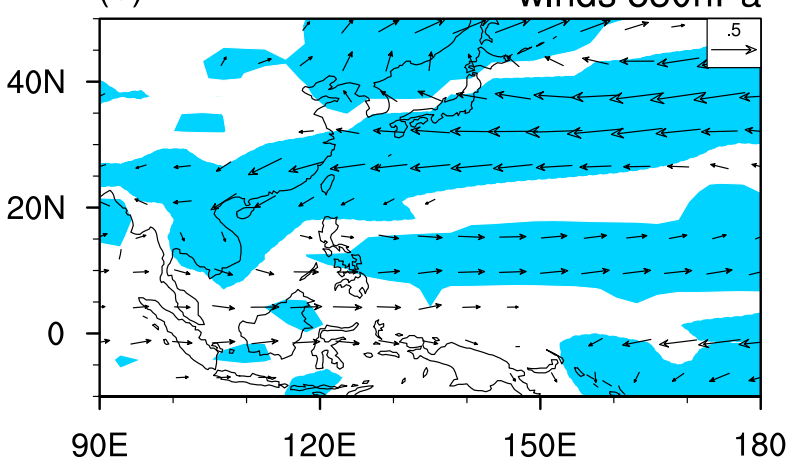

FIG. 13. Summer SLP (hPa), and 850-hPa wind $\left(\mathrm{m} \mathrm{s}^{-1}\right)$ anomalies regressed upon the preceding normalized spring $\mathrm{AO}$ index based on the historical simulations of the BNU-ESM model over 1850-2005. Stippling region in (a) indicates SLP anomalies significant at the $95 \%$ confidence level. Shading in (b) indicates either direction of wind anomalies significant at the $95 \%$ confidence level. Wind anomalies less than $0.1 \mathrm{~m} \mathrm{~s}^{-1}$ in both directions are omitted in (b).

The correlation coefficient between the spring AO index and the following EASM index is 0.23 from 1850 to 2005 (a total of 156 years), significant at the $99 \%$ confidence level. Figure 13 displays MJJ SLP and 850$\mathrm{hPa}$ winds anomalies obtained by regression upon the preceding normalized spring (MAM average) AO index for the period 1850-2005. During positive spring AO phase, marked negative SLP anomalies with an anomalous cyclone appear in the following summer over the subtropical western North Pacific, well consistent with the observed results (Gong et al. 2011). The anomalous cyclone over the subtropical WNP is a key system in relaying the impact of the spring AO on the EASM (Gong et al. 2011). The above results are consistent with Gao et al. (2016), confirming that the BNU-ESM historical simulation can well reproduce the spring AO-EASM connection.

The modulation effect of the AMO on the spring AOEASM connection can also be well captured by the
BNU-ESM simulation. During the + AMO phase (a total of 75 years), the correlation coefficient between the spring AO index and the EASM index is 0.14 , which is statistically insignificant. In contrast, during the - AMO phase (a total of 85 years), the spring AO has a pronounced positive relationship with the EASM, with the correlation coefficient being 0.34 , which is significant at the $99 \%$ confidence level. Figure 14 displays MJJ SLP and $850-\mathrm{hPa}$ winds anomalies regressed upon the preceding normalized spring $\mathrm{AO}$ index for the $+\mathrm{AMO}$ and -AMO phases. It is clear that the negative SLP anomalies and cyclonic anomaly over the subtropical WNP for the -AMO phase are similar to those shown in Fig. 13 but with stronger amplitude. This confirms that the spring $\mathrm{AO}$ has a significant impact on the EASM during the -AMO phase in the BNU-ESM simulation. By contrast, centers of the negative SLP and cyclonic anomalies (Figs. 14a,c) are weaker and located more northeastward during the $+\mathrm{AMO}$ phase compared to those during the -AMO phase (Figs. 14b,d), consistent with the observed (Fig. 4). As such, the spring AOEASM connection is weak during the + AMO phase.

Observational results indicate that AMO impact on the spring AO-EASM relation occurs through modulating the Pacific center of the spring AO. Figure 15 displays spring SLP and 500-hPa geopotential height anomalies obtained by regression upon the simultaneous normalized spring AO index for the +AMO and - AMO phases. The Pacific center of the spring AO during the $-\mathrm{AMO}$ phase (Figs. 15b,d) is about 3 times larger than that during the + AMO phase (Figs. 15a,c), similar to the observations. The above results generally show that the significant modulation effect of the AMO on the Pacific center of the spring AO and the spring AO-EASM connection can be well reproduced by the BNU-ESM historical simulation. Notice that this study only uses a single coupled model to examine the reproducibility of the spring AO-EASM relation modulated by the AMO. More state-of-the-art coupled models participating in CMIP5/6 will be employed to further understand to the modulation effect of the AMO on the spring AO-EASM connection.

\section{Summary and discussion}

Previous studies have suggested that the boreal spring AO can significantly influence the following EASM variation on the interannual time scale (Gong and Ho 2003; Gong et al. 2011). Two recent studies indicated that the spring AO-EASM connection was unstable in the past (Gao et al. 2014; Chen et al. 2015). The present study presents observational evidence to demonstrate that the AMO has a significant modulation effect on the 

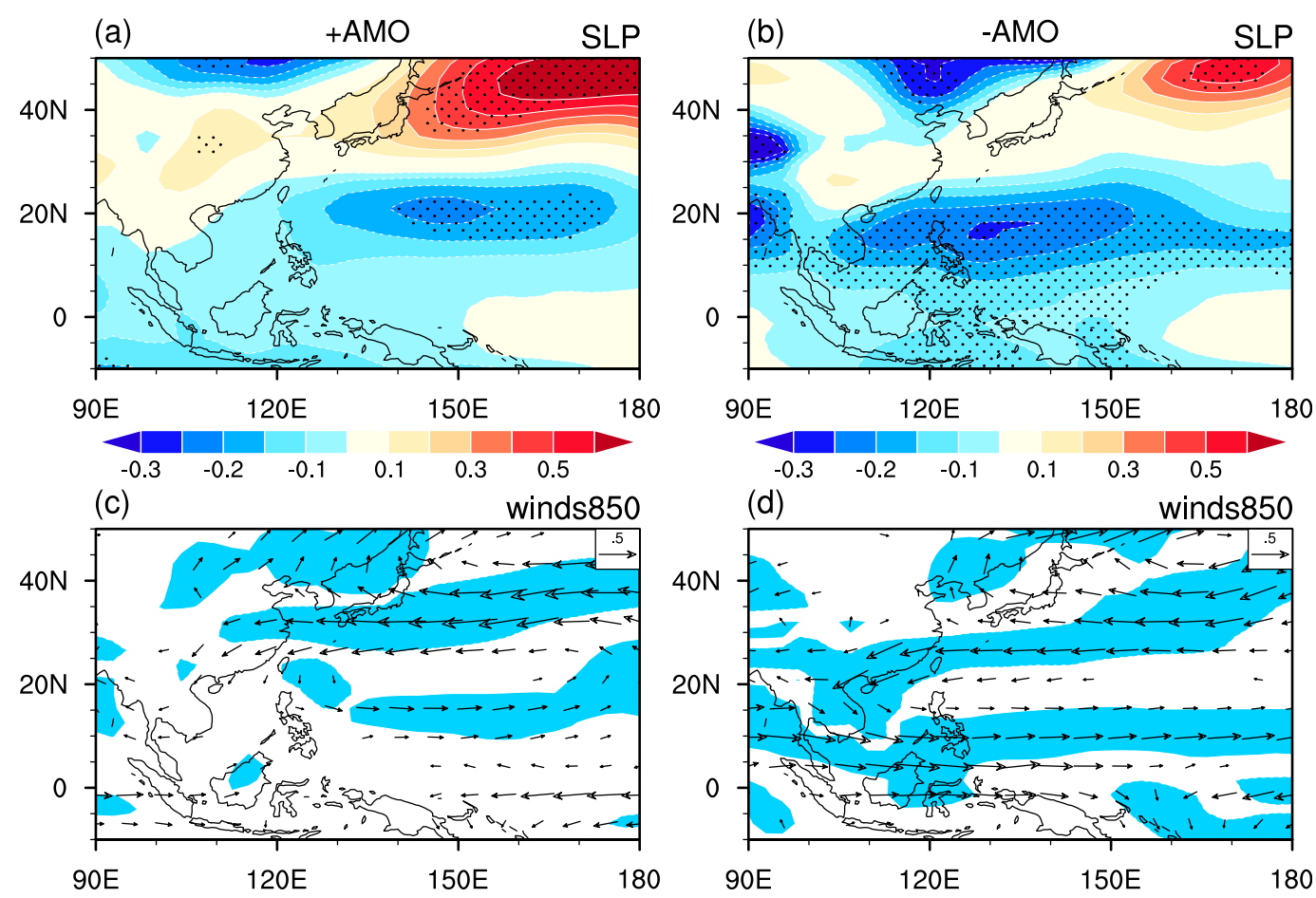

FIG. 14. Summer (a),(b) SLP (hPa) and (c),(d) 850-hPa wind $\left(\mathrm{m} \mathrm{s}^{-1}\right.$ ) anomalies regressed upon the preceding normalized spring AO index based on the historical simulations of the BNU-ESM model over 1850-2005 for the (left) + AMO and (right) - AMO phases. Stippled regions in (a) and (b) indicate SLP anomalies significant at the $95 \%$ confidence level. Shading in (c) and (d) indicates either direction of wind anomalies significant at the $95 \%$ confidence level. Wind anomalies less than $0.1 \mathrm{~m} \mathrm{~s}^{-1}$ in both directions are omitted in (c) and (d).

relation between the spring AO and the EASM. The spring AO-EASM connection is weak during the positive AMO phase. By contrast, the spring AO has a notable connection with the EASM during the negative AMO phase. The processes of the modulation effect of the AMO on the spring AO-EASM connection are summarized in Fig. 16.

During the negative AMO phase, a significant meridional atmospheric anomaly pattern appears over the North Pacific, with a significant anticyclonic anomaly over the midlatitudes and a significant cyclonic anomaly over the subtropics. The cyclonic anomaly induces SST warming and enhances atmospheric heating (indicated by positive precipitation) over the subtropical North Pacific. The enhanced atmospheric heating in turn maintains the cyclonic anomaly over the subtropical North Pacific. Through the positive air-sea feedback (Gong et al. 2011; Chen et al. 2015), the spring AOinduced cyclonic anomaly over the subtropical western North Pacific maintains and shifts westward from spring to the following summer, which impacts the following EASM and East Asian climate (Fig. 16). However, during the + AMO phase, the spring AO-related atmospheric circulation anomalies are weak from spring to the following summer. As a result, the impact of the spring AO on the EASM is weak (Fig. 16).

The AMO influences the spring AO-EASM connection via changing the Pacific center of the spring $A O$ and related atmospheric circulation over the North Pacific (Fig. 16). The Pacific center of the spring AO over the midlatitude is strong during the - AMO phase, but weak during the + AMO phase (Fig. 16). The strong anticyclonic anomaly over the midlatitude North Pacific during the - AMO phase is favorable for the generation of the cyclonic anomaly over the subtropical North Pacific via wave-mean flow interaction, and contributes to the spring AO-EASM connection (Fig. 16). The AMO could impact the spatial structure of the spring $\mathrm{AO}$ via modulating the AL-IL oscillation. The AL-IL oscillation is much stronger during the $-\mathrm{AMO}$ than the + AMO phase (Fig. 16). Further analyses indicate that AMO modulates the AL-IL oscillation via changing the $\mathrm{AL}$ intensity. During the +AMO phase, the SST warming in the North Atlantic results in significant upward motion anomalies over the midlatitude North Atlantic. The outflows induced by the upper-level divergence over the North Atlantic converge over the midlatitude North Pacific and lead to compensating downward motion and positive 


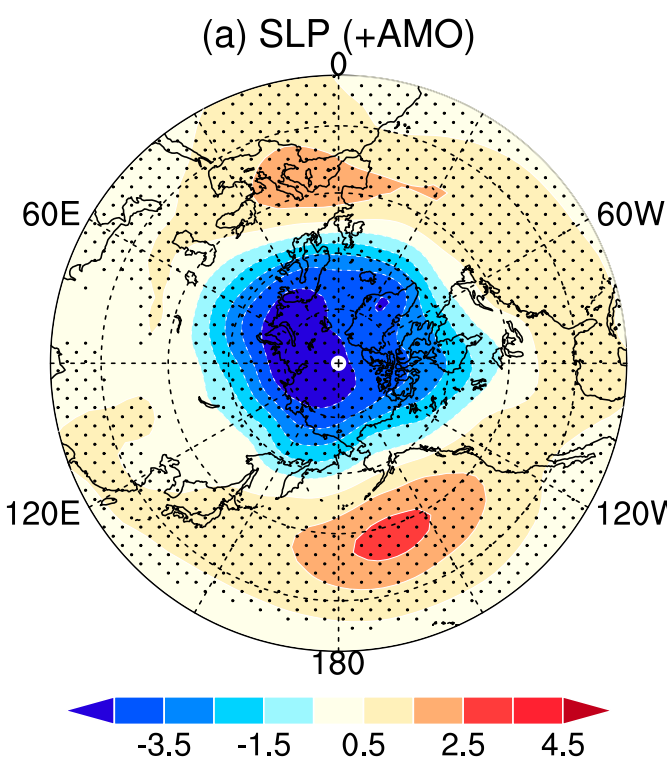

(c) hgt500 $(+\mathrm{AMO})$

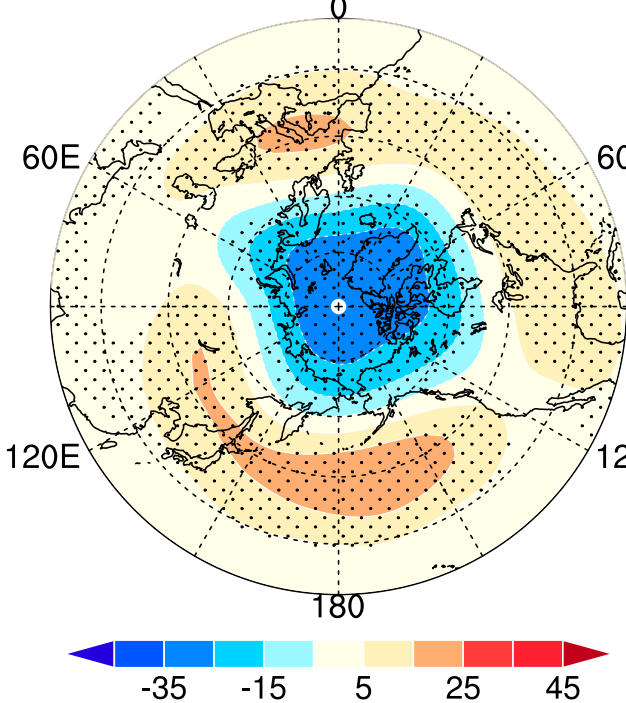

(b) $\operatorname{SLP}(-A M O)$

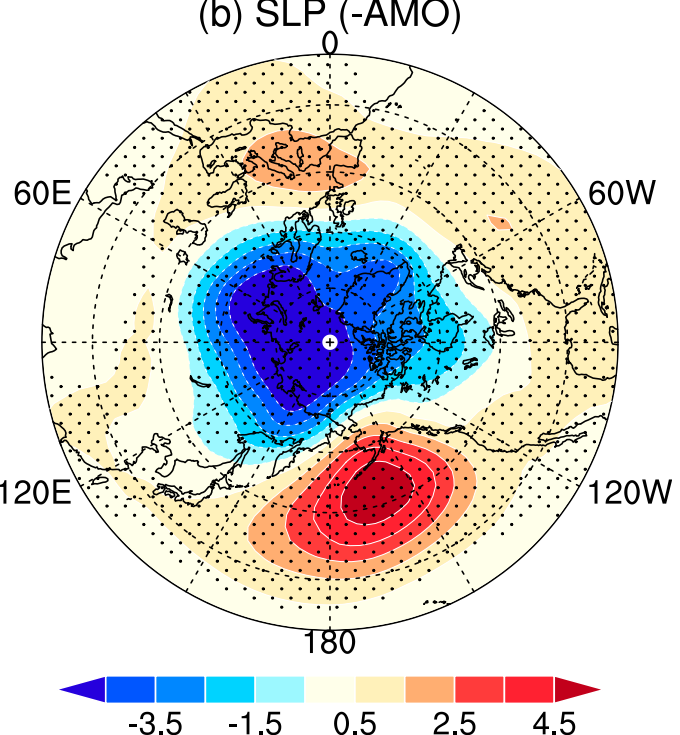

(d) hgt500 (-AMO)

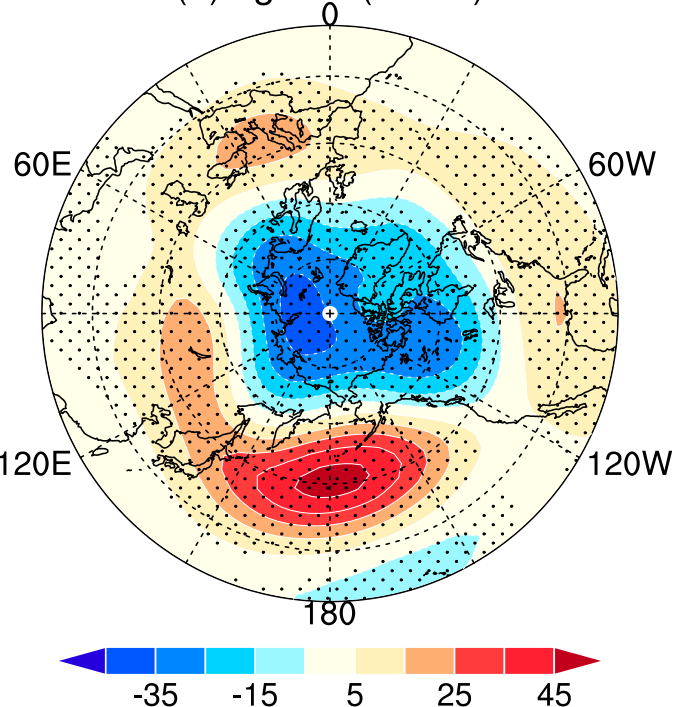

FIG. 15. Anomalies of (a),(b) spring SLP (hPa) and (c),(d) 500-hPa geopotential height (m) regressed upon the simultaneous normalized spring AO index for the (left) + AMO and (right) - AMO phases based on the historical simulations of the BNU-ESM model over 1850-2005. Stippled regions indicate anomalies significant at the $95 \%$ confidence level.

surface pressure anomalies, which result in weakening of the spring AL. Weak AL intensity during + AMO is unfavorable for generation of the $\mathrm{AL}-\mathrm{IL}$ oscillation and contributes to a weak Pacific component of the spring AO. The conditions are reversed for the $-\mathrm{AMO}$ phase. The significant modulation effect of the AMO on the relationship between the spring AO and EASM is confirmed by the long historical simulation in a coupled climate model.

Several recent studies indicated that summertime SST anomalies in the tropical North Atlantic (TNA) can exert impacts on the EASM variation via modulating the anomalous anticyclone over the subtropical western North Pacific (e.g., Rong et al. 2010; Chen et al. 2018a,b; Choi and Ahn 2019; Zhao et al. 2019). From Fig. 6, a significant tripolar SST anomaly pattern is seen in the North Atlantic during two phases of the AMO, with SST cooling in the tropics and midlatitude of the North Atlantic and SST warming in the subtropical western North Atlantic. In addition, correlation coefficients between the spring AO index and the TNA SST index 


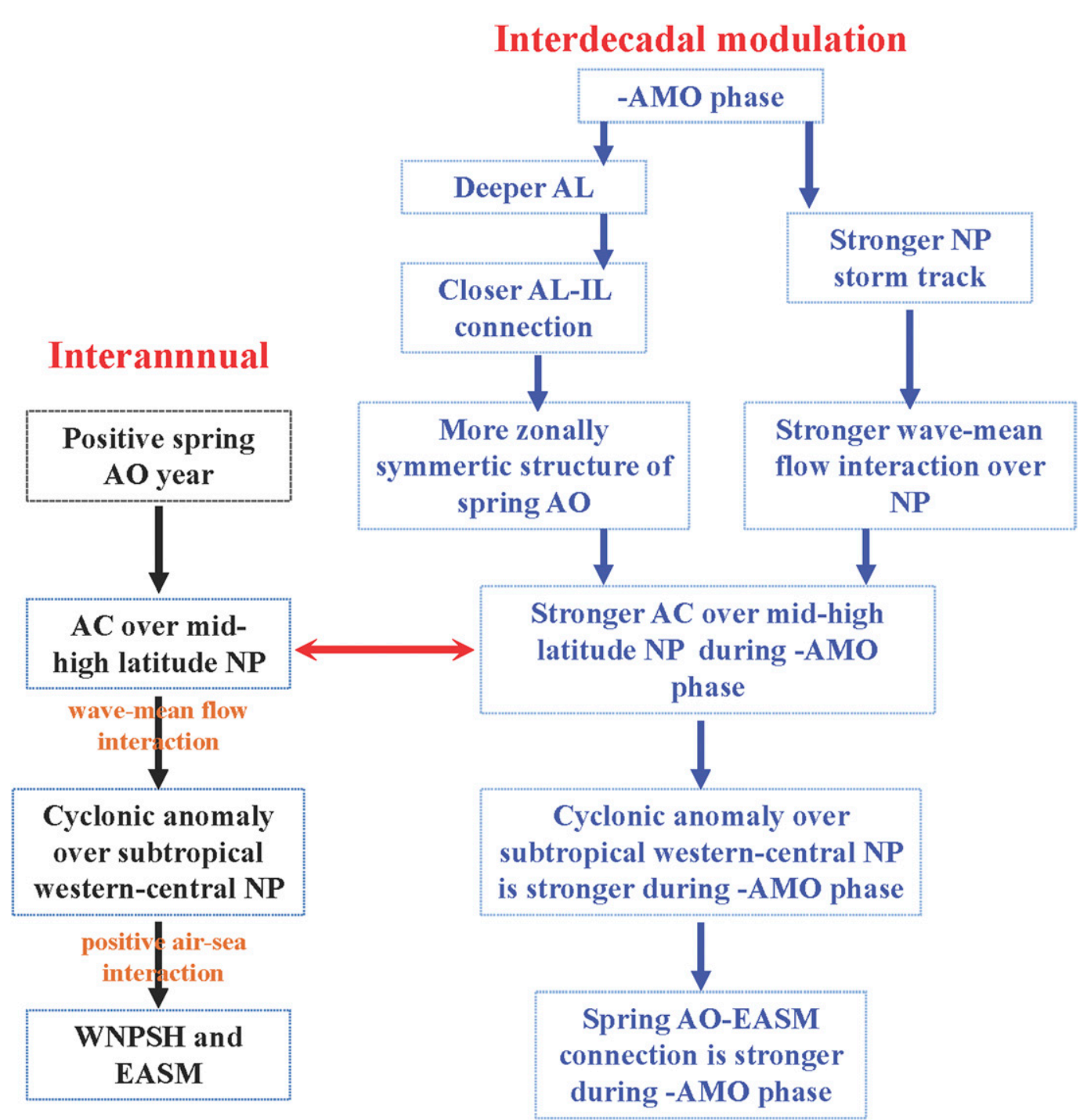

FIG. 16. A mechanism diagram displaying the processes for the interdecadal modulation of the AMO on the spring AO-EASM connection. The abbreviations AC, NP, AL, and IL denote anticyclonic anomaly, North Pacific, Aleutian low, and Icelandic low, respectively.

during + AMO and $-\mathrm{AMO}$ are -0.49 and 0.42 , respectively, both significant at the $95 \%$ confidence level. The NTA SST index is defined as region-mean SST anomalies over $0^{\circ}-20^{\circ} \mathrm{N}, 0^{\circ}-80^{\circ} \mathrm{W}$. This indicates that spring AO has a significant connection with the NTA SST during both phases of the AMO. Thus, this implies that impact of the AMO on the spring AO-EASM connection may not occur via modulating the spring AO-related SST anomalies in the TNA.

Studies indicated that change in the summertime Okhotsk high can impact EASM variation via modulating the subtropical monsoon front (Ding and Sikka 2006; Wu et al. 2009). A comparison of Figs. $4 \mathrm{a}$ and $4 \mathrm{~b}$ indicates that SLP anomalies in summer around the
Okhotsk Sea in association with the spring AO seem to exhibit a large difference between - AMO and + AMO phases. Following Ogi et al. (2004), the Okhotsk high index (OHI) is defined as region-mean SLP anomalies over $50^{\circ}-60^{\circ} \mathrm{N}, 140^{\circ}-160^{\circ} \mathrm{E}$. The correlation coefficient between the spring AO index and summer OHI during the $-\mathrm{AMO}$ phase (a total of 32 years) is 0.34 , significant at the $90 \%$ confidence level (but cannot pass the $95 \%$ confidence level). By contrast, during + AMO, the correlation coefficient between the spring $\mathrm{AO}$ index and the summer $\mathrm{OHI}$ is only -0.05 , which is much weaker than that during - AMO phase. This implies that change in the spring AO-related Okhotsk high during different phases of the AMO may partly contribute to the 
difference in the spring AO-EASM relation. The detailed physical processes for the impact of the AMO on the summertime Okhotsk high remain to be explored.

Over the North Pacific, there exist two prominent interdecadal climate variability modes, the PDO and NPGO. The PDO is generally regarded as the leading EOF mode of SST anomalies in the North Pacific, and its positive (negative) phase features SST cooling (warming) in the central North Pacific encircled by SST warming (cooling) along the coastline of North America (Mantua et al. 1997; Mantua and Hare 2002). In addition, the positive (negative) phase of the PDO is associated with a stronger (weaker) AL (Mantua et al. 1997; Mantua and Hare 2002). The NPGO is considered as the second EOF mode of sea surface height anomalies in the North Pacific, and it represents decadal changes in the subtropical and subpolar gyres in the North Pacific (Di Lorenzo et al. 2008, 2009). Do the two above-mentioned North Pacific decadal variability modes (i.e., PDO and NPGO) have an impact on the spring AO-EASM relation? To address this issue, we have calculated correlation coefficients of the spring $\mathrm{AO}$ index with the three EASM indices during different phases of the PDO and NPGO (Table 1). Results indicate that the spring AO has a significant correlation with the following EASM indices during positive PDO and negative NPGO phase (Table 1). By contrast, during negative PDO and positive NPGO phase, the spring AO-EASM relation is weak (Table 1). This indicates that the PDO and NPGO may also partly contribute to change in the spring AOEASM connection. The detailed physical processes responsible for impacts of the PDO/NPGO on the spring AO-EASM relation as well as the combined effects of the AMO, PDO and NPGO on the connection of the spring AO with the EASM are worthy of further investigation.

Acknowledgments. We thank three anonymous reviewers for their constructive suggestions, which helped to improve the paper. This study is jointly supported by the National Key Research and Development Program of China (Grant 2018YFA0605604) and the National Natural Science Foundation of China grants (41605050, 41530425, 41775080, and 41721004). The NCEP-NCAR reanalysis data are obtained from https://www.esrl.noaa.gov/ $\mathrm{psd} /$ data/gridded/data.ncep.reanalysis.html. The ERSSTv3b SST data are derived from https://www.esrl.noaa.gov/psd/ data/gridded/. The 20CRV2 reanalysis data are obtained from https://www.esrl.noaa.gov/psd/data/gridded/ data.20thC_ReanV2.html. The AMO index is derived from https://www.esrl.noaa.gov/psd/data/timeseries/AMO/. The historical simulations of BNU-ESM are obtained from https://esgf-node.llnl.gov/projects/esgf-1lnl/. The
PDO index is derived from https://www.esrl.noaa.gov/ $\mathrm{psd} /$ data/correlation/pdo.data. The NPGO index is obtained from http://www.o3d.org/npgo/.

\section{REFERENCES}

Cai, M., S. Yang, H. van den Dool, and V. Kousky, 2007: Dynamical implications of the orientation of atmospheric eddies: A local energetics perspective. Tellus, 59A, 127-140, https://doi.org/10.1111/j.1600-0870.2006.00213.x.

Chang, C.-P., Y. Zhang, and T. Li, 2000: Interannual and interdecadal variations of the East Asian summer monsoon and tropical Pacific SSTs. Part I: Roles of the subtropical ridge. J. Climate, 13, 4310-4325, https://doi.org/10.1175/1520-0442(2000) $013<4310$ :IAIVOT $>2.0 . \mathrm{CO} ; 2$

, Y. Ding, and N.-C. Lau, 2011: The Global Monsoon System: Research and Forecast. World Scientific, 594 pp.

Chen, S. F., B. Yu, and W. Chen, 2014: An analysis on the physical process of the influence of AO on ENSO. Climate Dyn., 42, 973-989, https://doi.org/10.1007/s00382-012-1654-z.

- W. Chen, and R. Wu, 2015: An interdecadal change in the relationship between boreal spring Arctic Oscillation and the East Asian summer monsoon around the early 1970s. J. Climate, 28, 1527-1542, https://doi.org/10.1175/JCLI-D-1400409.1.

,$- \ldots$, and B. Yu, 2017: The influence of boreal spring Arctic oscillation on the subsequent winter ENSO in CMIP5 models. Climate Dyn., 48, 2949-2965, https://doi.org/10.1007/s00382016-3243-z.

, R. Wu, and W. Chen, 2018a: Modulation of spring northern tropical Atlantic sea surface temperature on the El NiñoSouthern Oscillation-East Asian summer monsoon connection. Int. J. Climatol., 38, 5020-5029, https://doi.org/10.1002/joc.5710.

,$- \ldots$, and $-2018 \mathrm{~b}$ : A strengthened impact of November Arctic Oscillation on subsequent tropical Pacific sea surface temperature variation since the late-1970s. Climate Dyn., 51, 511-529, https://doi.org/10.1007/s00382-017-3937-x.

Cheng, Q., and B. Tan, 2019: On the variation of the Pacific center: A revisit to the physical nature of Arctic Oscillation. Climate Dyn., 53, 1233-1243, https://doi.org/10.1007/s00382-018-4583-7.

Choi, Y. W., and J. B. Ahn, 2019: Possible mechanisms for the coupling between late spring sea surface temperature anomalies over tropical Atlantic and East Asian summer monsoon. Climate Dyn., 53, 6995-7009, https://doi.org/10.1007/s00382019-04970-3.

Compo, G. P., and Coauthors, 2011: The Twentieth Century Reanalysis Project. Quart. J. Roy. Meteor. Soc., 137, 1-28, https://doi.org/10.1002/qj.776.

Dai, P., and B. Tan, 2017: The nature of the Arctic Oscillation and diversity of the extreme surface weather anomalies it generates. J. Climate, 30, 5563-5584, https://doi.org/10.1175/JCLI-D-16-0467.1.

Deser, C., M. A. Alexander, S. Xie, and A. Phillips, 2010: Sea surface temperature variability: Patterns and mechanisms. Annu. Rev. Mar. Sci., 2, 115-143, https://doi.org/10.1146/ annurev-marine-120408-151453.

Dickinson, R. E., A. Henderson-Sellers, and P. J. Kennedy, 1993: Biosphere-Atmosphere Transfer Scheme (BATS) version 1e as coupled to the NCAR Community Climate Model. NCAR Tech. Note NCAR/TN-387+STR, 72 pp.

Di Lorenzo, E., and Coauthors, 2008: North Pacific Gyre Oscillation links ocean climate and ecosystem change. Geophys. Res. Lett., 35, L08607, https://doi.org/10.1029/2007GL032838. 
_- and Coauthors, 2009: Nutrient and salinity decadal variations in the central and eastern North Pacific. Geophys. Res. Lett., 36, L14601, https://doi.org/10.1029/2009GL038261.

Ding, Q. H., and B. Wang, 2005: Circumglobal teleconnection in the Northern Hemisphere summer. J. Climate, 18, 3483-3505, https://doi.org/10.1175/JCLI3473.1.

Ding, T., Y. Yuan, J. M. Zhang, and H. Gao, 2019: 2018: The hottest summer in China and possible causes. J. Meteor. Res., 33, 577-592, https://doi.org/10.1007/s13351-019-8178-y.

Ding, Y. H., 1994: Monsoons over China. Kluwer Academic, 420 pp.

— , and D. R. Sikka, 2006: Synoptic systems and weather. The Asian Monsoon, B. Wang, Ed., Springer, 131-201.

Duchon, C. E., 1979: Lanczos filtering in one and two dimensions. J. Appl. Meteor., 18, 1016-1022, https://doi.org/10.1175/15200450(1979)018<1016:LFIOAT >2.0.CO;2.

Enfield, D. B., A. M. Mestas-Nuñez, and P. J. Trimble, 2001: The Atlantic multidecadal oscillation and its relation to rainfall and river flows in the continental U.S. Geophys. Res. Lett., 28 , 2077-2080, https://doi.org/10.1029/2000GL012745.

Feng, M., B. J. Wang, and S. Q. Xiong, 2000: Analysis on the abnormality of general circulation and sea temperature in relation to the flood water of Yangtze River in 1998. Resour. Environ. Yangtze Basin, 9, 112-117, http://doi.org/10.3969/ j.issn.1004-8227.2000.01.017.

Gao, M. N., J. Yang, D.-Y. Gong, and S. J. Kim, 2014: Unstable relationship between spring Arctic Oscillation and East Asian summer monsoon. Int. J. Climatol., 34, 2522-2528, https:// doi.org/10.1002/joc.3849.

, H. He, and S. Kim, 2016: Spring Arctic oscillationwestern North Pacific connection in CMIP5 models. Int. J. Climatol., 36, 2093-2102, https://doi.org/10.1002/joc.4486.

Geng, X., W. J. Zhang, M. F. Stuecker, P. Liu, F. F. Jin, and G. R. Tan, 2017: Decadal modulation of the ENSO-East Asian winter monsoon relationship by the Atlantic multidecadal oscillation. Climate Dyn., 49, 2531-2544, https://doi.org/10.1007/s00382016-3465-0.

Gill, A. E., 1980: Some simple solutions for heat-induced tropical circulation. Quart. J. Roy. Meteor. Soc., 106, 447-462, https:// doi.org/10.1002/qj.49710644905.

Gong, D.-Y., and C.-H. Ho, 2003: Arctic Oscillation signals in the East Asian summer monsoon. J. Geophys. Res., 108, 4066, https://doi.org/10.1029/2002JD002193.

— J. Zhu, and S. Wang, 2002: Significant relationship between spring $\mathrm{AO}$ and the summer rainfall along the Yangtze River. Chin. Sci. Bull., 47, 948-952, https://doi.org/10.1360/02tb9212.

_ J. Yang, S. J. Kim, Y. Q. Gao, D. Guo, T. J. Zhou, and M. Hu, 2011: Spring Arctic Oscillation-East Asian summer monsoon connection through circulation changes over the western North Pacific. Climate Dyn., 37, 2199-2216, https://doi.org/ 10.1007/s00382-011-1041-1.

Griffies, S. M., 2010: Elements of MOM4p1. GFDL Ocean Group Tech. Rep. 6, NOAA/Geophysical Fluid Dynamics Laboratory, 444 pp.

Honda, M., and H. Nakamura, 2001: Interannual seesaw between the Aleutian and Icelandic lows. Part II: Its significance in the interannual variability over the wintertime Northern Hemisphere. J. Climate, 14, 4512-4529, https://doi.org/10.1175/1520-0442(2001) 014<4512:ISBTAA $>2.0 . \mathrm{CO} ; 2$.

Hu, M., D.-Y. Gong, and R. Mao, 2013: Possible influence of February-April Arctic Oscillation on the ITCZ activity of western-central Pacific (in Chinese). J. Trop. Meteor., 29, $55-65$.
Huang, B., and Coauthors, 2017: Extended Reconstructed Sea Surface Temperature version 5 (ERSSTv5), upgrades, validations, and intercomparisons. J. Climate, 30, 8179-8205, https://doi.org/10.1175/JCLI-D-16-0836.1.

Huang, R., and F. Sun, 1992: Impacts of the tropical western Pacific on the East Asian summer monsoon. J. Meteor. Soc. Japan, 70, 243-256, https://doi.org/10.2151/jmsj1965.70.1B_243.

_ R. H. Zhang, and Q. Y. Zhang, 2000: The 1997/98 ENSO cycle and its impact on summer climate anomalies in East Asia. Adv. Atmos. Sci., 17, 348-362, https://doi.org/10.1007/ s00376-000-0028-3.

, J. L. Chen, L. T. Zhou, and Q. Y. Zhang, 2003: Studies on the relationship between the severe climatic disasters in China and the East Asia climate system. Chin. J. Atmos. Sci., 27, 770-787. , W. Chen, B. Yang, and R. Zhang, 2004: Recent advances in studies of the interaction between the East Asian winter and summer monsoons and ENSO cycle. Adv. Atmos. Sci., 21, 407-424, https://doi.org/10.1007/BF02915568.

— J. J. Chen, L. Wang, and Z. Lin, 2012: Characteristics, processes, and causes of the spatio-temporal variabilities of the East Asian monsoon system. Adv. Atmos. Sci., 29, 910-942, https://doi.org/10.1007/s00376-012-2015-x.

Hunke, E. C., and W. H. Lipscomb, 2010: CICE: The Los Alamos Sea Ice Model user's manual, version 4.1. Los Alamos National Laboratory Tech. Rep. LA-CC-06-012, 76 pp.

Hurrell, J. W., 1995: Decadal trends in the North Atlantic Oscillation. Science, 269, 676-679, https://doi.org/10.1126/science.269.5224.676. , and H. van Loon, 1997: Decadal variations in climate associated with the North Atlantic Oscillation. Climatic Change at High Elevation Sites, H. F. Diaz, M. Beniston, and R. Bradley, Eds., Springer, 69-94.

Ji, D., and Coauthors, 2014: Description and basic evaluation of Beijing Normal University Earth System Model (BNU-ESM) version 1. Geosci. Model Dev., 7, 2039-2064, https://doi.org/ 10.5194/gmd-7-2039-2014.

Joshi, M. K., and K. L. Ha, 2019: Fidelity of CMIP5-simulated teleconnection between Atlantic multidecadal oscillation and Indian summer monsoon rainfall. Climate Dyn., 52, 41574176, https://doi.org/10.1007/s00382-018-4376-z.

Kalnay, E., and Coauthors, 1996: The NCEP/NCAR 40-Year Reanalysis Project. Bull. Amer. Meteor. Soc., 77, 437-471, https://doi.org/ 10.1175/1520-0477(1996)077<0437:TNYRP>2.0.CO;2.

Kavvada, A., A. Ruiz-Barradas, and S. Nigam, 2013: AMO's structure and climate footprint in observations and IPCC AR5 climate simulations. Climate Dyn., 41, 1345-1364, https:// doi.org/10.1007/s00382-013-1712-1.

Kerr, R. A., 2000: A North Atlantic climate pacemaker for the centuries. Science, 288, 1984-1985, https://doi.org/10.1126/ science.288.5473.1984.

Lau, K., and H. Weng, 2001: Coherent modes of global SST and summer rainfall over China: An assessment of the regional impacts of the 1997-98 El Niño. J. Climate, 14, 1294-1308, https://doi.org/10.1175/1520-0442(2001)014<1294:CMOGSA > 2.0.CO;2.

Lau, N. C., 1988: Variability of the observed midlatitude storm tracks in relation to low-frequency changes in the circulation pattern. J. Atmos. Sci., 45, 2718-2743, https://doi.org/10.1175/ 1520-0469(1988)045<2718:VOTOMS > 2.0.CO;2.

Li, C. Y., and Coauthors, 2009: The Study of Meteorological Disasters and Chinese Response (in Chinese). China Meteorological Press, $187 \mathrm{pp}$.

Li, F., Y. J. Orsolini, H. J. Wang, Y. Q. Gao, and S. P. He, 2018: Modulation of the Aleutian-Icelandic low seesaw and its 
surface impacts by the Atlantic multidecadal oscillation. $A d v$. Atmos. Sci., 35, 95-105, https://doi.org/10.1007/s00376-0177028-z.

Li, S. L., L. R. Ji, W. T. Lin, and Y. Q. Ni, 2001: The maintenance of the blocking over the Ural Mountains during the second Meiyu period in the summer of 1998. Adv. Atmos. Sci., 18, 87105, https://doi.org/10.1007/s00376-001-0006-4.

Li, X., W. Zhou, and D. Chen, 2014: Water vapor transport and moisture budget over eastern China: Remote forcing from the two types of El Niño. J. Climate, 27, 8778-8792, https://doi.org/ 10.1175/JCLI-D-14-00049.1.

Limpasuvan, V., and D. L. Hartmann, 1999: Eddies and the annular modes of climate variability. Geophys. Res. Lett., 26, 31333136, https://doi.org/10.1029/1999GL010478.

$\longrightarrow$, and - , 2000: Wave-maintained annular modes of climate variability. J. Climate, 13, 4414-4429, https://doi.org/10.1175/ 1520-0442(2000)013<4414:WMAMOC $>2.0 . C O ;$.

Lorenz, D. J., and D. L. Hartmann, 2003: Eddy-zonal flow feedback in the Northern Hemisphere winter. J. Climate, 16, 1212-1227, https://doi.org/10.1175/1520-0442(2003)16<1212: EFFITN>2.0.CO;2.

Lu, R., 2002: Indices of the summertime western North Pacific subtropical high. Adv. Atmos. Sci., 19, 1004-1028, https:// doi.org/10.1007/s00376-002-0061-5.

Mantua, N. J., and S. R. Hare, 2002: The Pacific decadal oscillation. J. Oceanogr., 58, 35-44, https://doi.org/10.1023/A:1015820616384.

—_ - Y Y. Zhang, J. M. Wallace, and R. Francis, 1997: A Pacific interdecadal climate oscillation with impacts on salmon production. Bull. Amer. Meteor. Soc., 78, 1069-1079, https://doi.org/ 10.1175/1520-0477(1997)078<1069:APICOW>2.0.CO;2.

Neale, R. B., J. Richter, S. Park, P. H. Lauritzen, S. J. Vavrus, P. J. Rasch, and M. Zhang, 2013: The mean climate of the Community Atmosphere Model (CAM4) in forced SST and fully coupled experiments. J. Climate, 26, 5150-5168, https:// doi.org/10.1175/JCLI-D-12-00236.1.

Nitta, T., 1987: Convective activities in the tropical western Pacific and their impact on the Northern Hemisphere summer circulation. J. Meteor. Soc. Japan, 65, 373-390, https://doi.org/ 10.2151/jmsj1965.65.3_373.

Ogi, M., Y. Tachibana, and K. Yamazaki, 2004: The connectivity of the winter North Atlantic Oscillation (NAO) and the summer Okhotsk high. J. Meteor. Soc. Japan, 82, 905-913, https:// doi.org/10.2151/jmsj.2004.905.

Park, J., and T. Li, 2019: Interdecadal modulation of El Niñotropical North Atlantic teleconnection by the Atlantic multidecadal oscillation. Climate Dyn., 52, 5345-5360, https:// doi.org/10.1007/s00382-018-4452-4.

Peings, Y., and G. Magnusdottir, 2014: Forcing of the wintertime atmospheric circulation by the multidecadal fluctuations of the North Atlantic Ocean. Environ. Res. Lett., 9, 034018, https:// doi.org/10.1088/1748-9326/9/3/034018.

Rong, X. Y., R. H. Zhang, and T. Li, 2010: Impacts of Atlantic sea surface temperature anomalies on Indo-East Asian summer monsoon-ENSO relationship. Chin. Sci. Bull., 55, 2458-2468, https://doi.org/10.1007/s11434-010-3098-3.

Shi, N., and H. Nakamura, 2014: Multi-decadal modulations in the Aleutian-Icelandic low seesaw and the axial symmetry of the Arctic Oscillation signature, as revealed in the 20th century reanalysis. Tellus, 66A, 22660, https://doi.org/10.3402/tellusa.v66.22660.

Smith, T. M., R. W. Reynolds, T. C. Peterson, and J. Lawrimore, 2008: Improvements to NOAA's historical merged landocean surface temperature analysis (1880-2006). J. Climate, 21, 2283-2296, https://doi.org/10.1175/2007JCLI2100.1.
Smoliak, B. V., and J. M. Wallace, 2015: On the leading patterns of Northern Hemisphere sea level pressure variability. J. Atmos. Sci., 72, 3469-3486, https://doi.org/10.1175/JAS-D-14-0371.1.

Sun, C., F. Kucharski, J. P. Li, F.-F. Jin, I.-S. Kang, and R. Q. Ding, 2017: Western tropical Pacific multidecadal variability forced by the Atlantic multidecadal oscillation. Nat. Commun., 8, 15998, https://doi.org/10.1038/ncomms15998.

Sun, J., and B. Tan, 2013: Mechanism of the wintertime Aleutian low-Icelandic low seesaw. Geophys. Res. Lett., 40, 4103-4108, https://doi.org/10.1002/grl.50770.

Tao, S., and L. Chen, 1987: A review of recent research on the East Asian summer monsoon in China. Monsoon Meteorology, C. P. Chang and T. N. Krishnamurti, Eds., Oxford University Press, 60-92.

Thompson, D. W., and J. M. Wallace, 1998: The Arctic Oscillation signature in the wintertime geopotential height and temperature fields. Geophys. Res. Lett., 25, 1297-1300, https://doi.org/ 10.1029/98GL00950.

— , and - 2000: Annular modes in the extratropical circulation. Part I: Month-to-month variability. J. Climate, 13, 1000-1016, https:// doi.org/10.1175/1520-0442(2000)013<1000:AMITEC>2.0.CO;2.

- S. Lee, and M. P. Baldwin, 2003: Atmospheric processes governing the Northern Hemisphere annular mode/North Atlantic Oscillation. The North Atlantic Oscillation: Climatic Significance and Environmental Impact, J. W. Hurrell, Eds., American Geophysical Union, 81-112.

Wallace, J. M., and D. W. J. Thompson, 2002: The Pacific center of action of the Northern Hemisphere annular mode: Real or artifact? J. Climate, 15, 1987-1991, https://doi.org/10.1175/ 1520-0442(2002)015<1987:TPCOAO>2.0.CO;2.

Wang, B., and Z. Fan, 1999: Choice of South Asian summer monsoon indices. Bull. Amer. Meteor. Soc., 80, 629-638, https://doi.org/ 10.1175/1520-0477(1999)080<0629:COSASM > 2.0.CO;2.

- R. Wu, and X. Fu, 2000: Pacific-East Asian teleconnection: How does ENSO affect EastAsian climate? J. Climate, 13, 1517-1536, https://doi.org/10.1175/1520-0442(2000)013<1517: PEATHD $>2.0 . \mathrm{CO} ; 2$.

Wang, Q., and L. Zhang, 2018: Analysis of the August 2018 atmosphere circulation and weather. Meteor. Mon., 44, 15011508 .

_, Y. H. Ding, and Y. Jiang, 1998: Relationship between Asian monsoon activities and the precipitation over China mainland (in Chinese). Quart. J. Appl. Meteor, 9, 84-89.

Wang, W., W. Zhou, and D. Chen, 2014: Summer high temperature extremes in southeast China: Bonding with the El NiñoSouthern Oscillation and East Asian summer monsoon coupled system. J. Climate, 27, 4122-4138, https://doi.org/10.1175/ JCLI-D-13-00545.1.

Wegmann, M., Y. Orsolini, E. Dutra, O. Bulygina, A. Sterin, and S. Brönnimann, 2017: Eurasian snow depth in long-term climate reanalyses. Cryosphere, 11, 923-935, https://doi.org/ 10.5194/tc-11-923-2017.

Wu, R., and B. P. Kirtman, 2007: Observed relationship of spring and summer East Asian rainfall with winter and spring Eurasian snow. J. Climate, 20, 1285-1304, https://doi.org/ 10.1175/JCLI4068.1.

Wu, Z., and L. Yu, 2016: Seasonal prediction of the East Asian summer monsoon with a partial-least square model. Climate Dyn., 46, 3067-3078, https://doi.org/10.1007/s00382-015-2753-4. , B. Wang, J. Li, and F.-F. Jin, 2009: An empirical seasonal prediction model of the East Asian summer monsoon using ENSO and NAO. J. Geophys. Res., 114, D18120, https:// doi.org/10.1029/2009JD011733. 
Xiang, B. Q., B. Wang, and T. Li, 2013: A new paradigm for the predominance of standing central Pacific warming after the late 1990s. Climate Dyn., 41, 327-340, https://doi.org/10.1007/ s00382-012-1427-8.

Xie, S. P., K. M. Hu, J. Hafner, H. Tokinaga, Y. Du, G. Huang, and T. Sampe, 2009: Indian Ocean capacitor effect on Indo-western Pacific climate during the summer following El Niño. J. Climate, 22, 730-747, https://doi.org/10.1175/2008JCLI2544.1.

Yang, Y. M., S. An, B. Wang, and J. H. Park, 2019: A global-scale multidecadal variability driven by Atlantic multidecadal oscillation. Natl. Sci. Rev., https://doi.org/10.1093/nsr/nwz216, in press.

Yuan, Y., H. Gao, and Y. J. Liu, 2017: Analysis of the characteristics and causes of precipitation anomalies over eastern China in the summer of 2016. Meteor. Mon., 43, 115-121.

,-- , and T. Ding, 2020: The extremely north position of the western Pacific subtropical high in summer of 2018: Important role of the convective activities in the western Pacific. Int. J. Climatol., 40, 1361-1374, https://doi.org/10.1002/joc.6274.

Zhai, P., and Coauthors, 2016: The strong El Niño of 2015/16 and its dominant impacts on global and China's climate. J. Meteor. Res., 30, 283-297, https://doi.org/10.1007/s13351-016-6101-3.

Zhang, Q. Y., S. Y. Tao, and L. T. Chen, 2003: The interannual variability of East Asian summer monsoon indices and its association with the pattern of general circulation over East Asia (in Chinese). Acta Meteor. Sin., 61, 559-568.

Zhang, R., and T. L. Delworth, 2007: Impact of the Atlantic multidecadal oscillation on North Pacific climate variability.
Geophys. Res. Lett., 34, L23708, https://doi.org/10.1029/ 2007 GL031601.

Zhang, R. H., A. Sumi, and M. Kimoto, 1996: Impact of El Niño on the East Asian monsoon: A diagnostic study of the '86/87 and '91/92 events. J. Meteor. Soc. Japan, 74, 49-62, https://doi.org/ 10.2151/jmsj1965.74.1_49.

Zhao, P., Z. Zhou, and J. Liu, 2007: Variability of Tibetan spring snow and its associations with the hemispheric extratropical circulation and East Asian summer monsoon rainfall: An observational investigation. J. Climate, 20, 3942-3955, https:// doi.org/10.1175/JCLI4205.1.

Zhao, W., S. Chen, W. Chen, S. Yao, D. Nath, and B. Yu, 2019: Interannual variations of the rainy season withdrawal of the monsoon transitional zone in China. Climate Dyn., 53, 20312046, https://doi.org/10.1007/s00382-019-04762-9.

Zhou, P., L. Suo, J. Yuan, and B. Tan, 2012: The East Pacific wave train: Its variability and impact on the atmospheric circulation in the boreal winter. Adv. Atmos. Sci., 29, 471-483, https:// doi.org/10.1007/s00376-011-0216-3.

Zuo, J. Q., W. J. Li, C. H. Sun, L. Xu, and H. L. Ren, 2013: Impact of the North Atlantic sea surface temperature tripole on the East Asian summer monsoon. Adv. Atmos. Sci., 30, 11731186, https://doi.org/10.1007/s00376-012-2125-5.

,$--\longrightarrow$, and H. C. Ren, 2019: Remote forcing of the northern tropical Atlantic SST anomalies on the western North Pacific anomalous anticyclone. Climate Dyn., 52, 2837 2853, https://doi.org/10.1007/s00382-018-4298-9. 